\title{
Is There Mimicking Behavior in Firms' Trade Credit Decisions?
}

DOI:

$10.1561 / 114.00000003$

\section{Document Version}

Accepted author manuscript

Link to publication record in Manchester Research Explorer

\section{Citation for published version (APA):}

Rind, A. A., Boubaker, S., \& Dang, V. A. (2021). Is There Mimicking Behavior in Firms' Trade Credit Decisions? Review of Corporate Finance, 1(1-2), 81-134. https://doi.org/10.1561/114.00000003

\section{Published in:}

Review of Corporate Finance

\section{Citing this paper}

Please note that where the full-text provided on Manchester Research Explorer is the Author Accepted Manuscript or Proof version this may differ from the final Published version. If citing, it is advised that you check and use the publisher's definitive version.

\section{General rights}

Copyright and moral rights for the publications made accessible in the Research Explorer are retained by the authors and/or other copyright owners and it is a condition of accessing publications that users recognise and abide by the legal requirements associated with these rights.

\section{Takedown policy}

If you believe that this document breaches copyright please refer to the University of Manchester's Takedown Procedures [http://man.ac.uk/04Y6Bo] or contact uml.scholarlycommunications@manchester.ac.uk providing relevant details, so we can investigate your claim.

\section{OPEN ACCESS}




\title{
Is There Mimicking Behavior in Firms' Trade Credit Decisions?
}

\author{
Asad Ali Rind ${ }^{1,2}$, Sabri Boubaker ${ }^{1,3}$ and Viet Anh Dang ${ }^{4 *}$ \\ ${ }^{1}$ IRG, Université Paris Est Créteil, France; asad-ali.rind@u-pec.fr \\ ${ }^{2}$ Iqra University, Karachi, Pakistan; asad-ali.rind@u-pec.fr \\ ${ }^{3}$ EM Normandie Business School, Métis Lab, France; \\ sboubaker@em-normandie.fr \\ ${ }^{4}$ Alliance Manchester Business School, University of Manchester, Manchester, \\ UK; vietanh.dang@manchester.ac.uk
}

\begin{abstract}
This paper investigates whether peer firms affect trade credit policy. Using data on US listed firms for the period 1997-2015, we document strong evidence of peer influence on trade credit provision. This result remains significant after using alternative trade credit measures, different peer proxies, and addressing endogeneity concerns using an instrumental variable approach based on the stock price shocks of industry peers. Our cross-sectional analysis further shows that peer effects in trade receivables only exist among suppliers that face fierce product market competition, consistent with the notion that firms closely mimic their peers due to competitive pressure. There is, however, mixed, and weak evidence on the argument that peer mimicking is driven by learning and reputational motives. Overall, our study highlights the important role of peer firm behavior in shaping a firm's trade credit policy.
\end{abstract}
Keywords: Trade credit, accounts receivable, firm behavior, peer effects, mimicking

JEL Codes: G30, G32, D21, D22

\footnotetext{
${ }^{*}$ We would like to thank the editors (Douglas Cumming and Chelsea Liu) and an anonymous referee for their helpful comments that have greatly improved our paper. We also acknowledge the helpful feedback from Imen Derouiche, Wael Rouatbi, Walid Saffar, and Syrine Sassi. The usual disclaimer applies.
} 


\section{Introduction}

Trade credit is one of the most important sources of short-term financing for companies around the world (Fisman and Love, 2003), funding around $90 \%$ of global merchandise trade (Klapper et al., 2012). As of 2018, trade receivables on the aggregate balance sheet of nonfinancial corporate businesses in the US stood at approximately 4.7 trillion US dollars, considerably higher than intellectual property products and inventories, both of which amounted to between 2.6 and 2.7 trillion US dollars. ${ }^{1}$ Empirical evidence suggests that trade receivables, as an important component of a firm's working capital policy, have major implications for firms' operations and performance (e.g., Kieschnick et al., 2013; Aktas et al., 2015; Box et al., 2018).

Given the prevalent usage of trade receivables and the importance of this policy for the corporate sector, prior theoretical research has studied various financing and non-financing motives for trade credit provision. ${ }^{2}$ Empirical research has also documented several firm-specific factors determining the use of accounts receivable (e.g., Mian and Smith, 1992; Petersen and Rajan, 1997). Recent evidence has further shown that trade credit provision is not only affected by firm characteristics but also driven by the environment in which the firm operates, such as macro-financial shocks (Choi and Kim, 2005), financial crises (e.g., Love et al., 2007; Garcia-Appendini and Montoriol-Garriga, 2013), and national culture (El Ghoul and Zheng, 2016). However, most of this strand of research implicitly assumes that firms manage trade credit policies in isolation and independently of the actions and characteristics of their rival firms that operate in the same industry and supply similar products. As such, the question of whether a firm's trade credit decisions are affected by those of its peers is still unanswered. This is an important omission in the literature given the recent evidence that peer firm behavior plays a central role in shaping corporate financial decisions (e.g., Leary and Roberts, 2014; Foucault and Frésard, 2014; Grennan, 2019).

Our paper fills this literature void by studying whether and why firms mimic the trade credit policies of their industry peers. Based on previous research (Lieberman and Asaba, 2006), we hypothesize that peer effects in

\footnotetext{
${ }^{1}$ Source: The Financial Accounts of the US (https://www.federalreserve.gov/releases/ z1/20190920/z1.pdf)

${ }^{2}$ Prior studies have documented several motives for the use of trade receivables, including financing (Schwartz, 1974; Petersen and Rajan, 1997), commercial (Ferris, 1981; Emery, 1984; Emery, 1987), and operational motives (Lee and Stowe, 1993; Long et al., 1993). According to the financing motive, trade credit presents advantages in information acquisition and monitoring (Biais and Gollier, 1997; Burkart and Ellingsen, 2004), enforcement and renegotiation (Wilner, 2000; Cuñat, 2007), and liquidation (Mian and Smith, 1992; Fabbri and Menichini, 2010). Trade receivables can also be used as a screening and price discrimination device in the presence of asymmetric information (Smith, 1987; Brennan et al., 1988).
} 
trade credit provision exist and operate through two main economic channels. First, the peer-based information channel suggests that trade credit mimicking is driven by learning and reputational motives. Managers that are less informed have strong incentives to learn from peer firms' information and follow their financing policies (Bikhchandani et al., 1992). In the context of trade credit, less informed suppliers may obtain private information about the industry's growth prospects by observing the amount of trade credit offered by peer firms. Those suppliers will then be able to use their peer-based learning to design appropriate policies, for instance, by extending or restricting trade credit, based on peer firms' decisions. Moreover, suppliers with high information asymmetry and reputational concerns may have strong incentives to imitate peer firms Scharfstein and Stein, 1990. Such suppliers may find it beneficial to mimic their peers' trade receivables, offering trade credit to buyers as a guarantee of product quality (Long et al., 1993) while building and maintaining their reputation. Overall, the above arguments suggest that trade receivables are positively affected by peer firm behavior because less informed managers and less established suppliers have strong learning and reputational motives for mimicking their industry peers.

The second economic channel, that is, the competition channel, predicts that fierce competitive pressure in the product market leads to mimicking in trade credit provision (e.g., Leary and Roberts, 2014). Drawn from rivalry-based models, the rationale behind this view is that mimicking behavior enables firms to deal with competitors' aggressive actions while maintaining their market power. In a competitive market, suppliers face the threat of customer switching and loss in sales and thus have strong incentives to extend trade credit to retain existing buyers and attract new ones (Fisman and Raturi, 2004). Put differently, suppliers employ trade receivables strategically to create a competitive advantage over their rivals (Fabbri and Klapper, 2016; Barrot, 2016). However, this behavior is likely to be mimicked by other suppliers, who also find it necessary to offer more trade credit to prevent customer switching and maintain their market share. Overall, in competitive product markets, peer firm behavior positively impacts firms' trade receivables.

To test the main prediction of peer effects in trade credit policies, we first identify peers using Hoberg and Phillips' (2016) text-based network industry classifications (TNIC). This approach defines a firm's peers based on the similarity between the firm's product descriptions and those of its peers, which better reflects how managers typically identify their competitors. An important advantage of using TNIC over traditional industry classifications is that it provides a firm-specific and dynamic measure of peers. Under TNIC each firm has its own set of unique peers, which varies over time depending on changes in the firm's product market descriptions relative to those of its peers. While we use TNIC-based peers in the main analysis, our results are robust 
to alternative methods for identifying peer firms based on traditional (static) industry classifications.

Our regression analysis examines whether a firm's trade receivables are positively associated with peer firm behavior, defined as the average trade receivables of TNIC-based peers. One challenge of this analysis is that using the OLS estimator leads to a biased estimate of peer effects due to a particular form of endogeneity, known as the reflection problem (Manski, 1993). This issue arises when regressing an outcome variable (i.e., trade receivables) on its group averages (i.e., peer trade receivables) as the regression may become spurious due to the endogenous selection of firms into peer groups. In addition, the results may be biased if there are common omitted factors that affect both the firm's trade receivables and those of its peers. To address these concerns, we follow recent research (Leary and Roberts, 2014; Grennan, 2019) and use peer idiosyncratic stock returns as a source of plausibly exogenous variation in peer effects. Our main analysis runs two-stage least squares (2SLS) regressions using this variable as an instrument for peer firm behavior. Our results are robust to alternative definitions of the instrument used, including a recently proposed instrumental variable that combines both industry and geography variations in peer trade receivables (Bustamante and Frésard, 2019).

Using a sample of publicly listed manufacturing firms in the US for the period 1997-2015, we document strong evidence of positive and significant peer influence on trade credit provision. The result holds after controlling for both firm and peer characteristics and survives a battery of robustness checks using alternative definitions of trade credit, peer firms, and instrumental variables. These results are not only statistically significant but also economically meaningful. A standard deviation (0.061) increase in peer trade receivables is associated with a $39 \%$ increase in firm trade receivables. Taken together, our findings provide strong empirical support for the hypothesis that peer firm behavior plays an important role in shaping trade credit policies.

We next study whether peer effects in trade credit provision operate through the peer-based information and/or competition channels. According to the first channel, peer influence should be more pronounced among firms with a higher degree of information asymmetry and a weaker reputation, which should have stronger learning and reputational motives. The second channel predicts that trade credit mimicking is more relevant among firms facing fierce competitive pressure from rivals in the product market. In our cross-sectional analysis, we document strong evidence in support of the second economic channel. The empirical results show that firms operating in highly competitive industries closely mimic their peers' trade receivables. However, the evidence on the role of peer-based information is weak and mixed. Firms with high information asymmetry and reputational concerns generally do not exhibit mimicking behavior, although there is some evidence that young firms do follow their peers' trade credit policies. We also document stronger trade credit peer effects 
for unconstrained firms and those operating in industries with standardized products; the former finding is again inconsistent with peer-based learning while the latter is in line with rivalry-based models. Taken together, these results suggest that trade credit mimicking is mainly driven by the competition channel.

Our paper contributes to the literature in three ways. First, our study adds to existing research on the determinants of trade receivables. Previous studies have documented a number of firm characteristics that affect trade credit policy (e.g., Mian and Smith, 1992; Long et al., 1993; Petersen and Rajan, 1997; Ng et al., 1999; Molina and Preve, 2009; Giannetti et al., 2011; Abdulla et al., 2020). ${ }^{3}$ We add to this strand of research by showing that a firm's trade credit is not only determined by internal firm-specific factors but is also affected by the environment in which the firm operates, particularly the trade credit policies of industry peers. Our analysis shows that the impact of peer firm behavior on accounts receivable is above and beyond that of firm-level determinants of trade credit. Given the role of trade receivables in improving firm performance and reducing the cost of doing business (e.g., Deloof, 2003; Deloof and Jegers, 1996; Ferrando and Mulier, 2013), an implication of our results is that managers should pay due attention to peer firms' trade credit policies when managing their own accounts receivable.

Second, our results contribute to a related body of literature documenting the importance of external factors for trade credit policy. As reviewed above, this literature shows that trade receivables are influenced by macroeconomic and cultural factors, including macro-financial shocks, financial crises, and a country's collectivism and uncertainty avoidance, among others (Nilsen, 2002; Choi and Kim, 2005; Love et al., 2007; Garcia-Appendini and MontoriolGarriga, 2013; El Ghoul and Zheng, 2016; Gonçalves et al., 2018). Our study highlights the importance of peer firm behavior in the product market for firm trade receivables. In addition, since our results show that trade credit peer effects are mainly driven by rivalry-based models, our study also adds to a related strand of research examining the impact of product market competition on trade credit provision (e.g., McMillan and Woodruff, 1999; Fisman and Raturi, 2004; Dass et al., 2015; Fabbri and Klapper, 2016; Chod et al., 2019). Our results suggest that competition not only affects the amount of trade credit provision but also acts as a channel through which peer effects operate. On the other hand, our study is related to previous studies on the impact of information asymmetry on trade credit decisions (Smith, 1987; Lee and Stowe,

\footnotetext{
${ }^{3}$ See, also, many other studies on trade credit, including those using non-U.S. data on small and private businesses, such as Deloof and Jegers (1996), Wilson and Summers (2002), Pike et al. (2005), Niskanen and Niskanen (2006), Cuñat (2007), Bougheas et al. (2009), Cull et al. (2009), García-Teruel and Martínez-Solano (2010a), García-Teruel and Martínez-Solano (2010b), Love and Zaidi (2010), Atanasova (2012), and Casey and O'Toole (2014), and McGuinness et al. (2018).
} 
1993). However, unlike those studies, we find that trade credit mimicking is unlikely to be driven by the peer-based information channel.

Third, our paper adds to a growing strand of corporate finance research on peer effects. This literature has documented evidence of mimicking in several financial decisions, including capital structure (MacKay and Phillips, 2005; Gao et al., 2011; Leary and Roberts, 2014; Francis et al., 2016a; Francis et al., 2016b), investment (Foucault and Frésard, 2014; Dougal et al., 2015), seasoned equity offerings (Billett et al., 2019), corporate social responsibility (Jiraporn et al., 2014; Husted et al., 2015; Cao et al., 2019), cash holdings (Chen et al., 2019), stock splits and payout policy (Kaustia and Rantala, 2015; Adhikari and Agrawal, 2018; Grennan, 2019), and real option exercise (Decaire et al., 2019). In addition, there is evidence that peer influence plays an important role in determining a firm's accounting restatements (Gleason et al., 2008), earnings forecasts and management (Kim et al., 2008; Bratten et al., 2015), corporate disclosures (Seo, 2017), corporate misconduct (Parsons et al., 2018), as well as CEO compensation and corporate governance (Bizjak et al., 2008; Albuquerque et al., 2013; Francis et al., 2016a; Fairburst and Nam, 2018). ${ }^{4}$ We add to this literature by documenting evidence of peer effects in trade receivables, an important, yet unexplored, working capital management policy.

In a recent paper, Gyimah et al. (2020) also focus on the impact of peer firms on trade credit policies. Our study differs from this work in two important ways. First, central to our empirical analysis is the identification of industry peers using textual analysis (Hoberg and Maksimovic, 2015), which, as mentioned above, is based on the similarity in the product descriptions of firms in their annual 10-K filings. Specifically, instead of simply considering peers to be those firms operating in the same standard industrial classifications (SIC) as in Gyimah et al. (2020), we identify industry membership following a more flexible and rigorous approach based on TNIC. Since the focus of trade credit policy is the underlying product being sold, the TNIC approach to mapping firms to industries based on the nature of the product and its description is superior to standard classifications based on production processes. Indeed, our approach yields a firm-specific and dynamic classification of industry membership, which changes corresponding to the underlying developments in firms' technologies and product descriptions. Since both a firm's industry membership and its definition of peers change following changes in the firm's product offerings due to common demand shocks, another advantage of our approach over the SIC method is that it better explains differences in firm-level characteristics

\footnotetext{
${ }^{4}$ Our firm-level evidence of peer mimicking in trade credit is also related to recent research on herding behavior and peer effects among individuals (e.g., Ahern et al., 2014; Bursztyn et al., 2014; Bailey et al., 2018), particularly financial analysts (e.g., Trueman, 1994; De Bondt, 1999; Welch, 2000), traders (Heimer, 2016), employees (Beshears et al., 2015; Ouimet and Tate, 2019), and financial advisors (Dimmock et al., 2018), as well as households (e.g., Georgarakos et al., 2014) and asset markets (e.g., Hott, 2009).
} 
(e.g., market risk, sales growth, and firm profitability) and ensures that the industry peers are exposed to the same shocks (Foucault and Frésard, 2014), another indication of firm relatedness. Overall, compared to Gyimah et al. (2020), our approach to identifying peer firms is more appropriate and helps reduce selection bias.

Second, in terms of the empirical findings and the channels through which peer effects operate, Gyimah et al. (2020) show that peer effects in trade credit policies are consistent with rivalry- and information-based explanations as well as learning motives. However, we find that peer mimicking behavior is mainly driven by the competition mechanism, while our extensive cross-sectional analysis provides little evidence in support of the peer-based information channel as well as learning and reputational motives. A potential explanation for the differences in the main results and economic mechanisms between our study and Gyimah et al. (2020) is again our use of a more accurate definition of industry membership. As mentioned above, the TNIC approach ensures that industry peers are more likely to be affected by common shocks, therefore strengthening our identification strategy and improving the consistency in the estimates of peer influence in our regression analysis, which relies on common equity shocks (e.g., idiosyncratic stock returns) as an instrumental variable.

The remainder of the paper is organized as follows. Section 2 develops our testable hypothesis. Section 3 describes the sample, descriptive statistics, and the main empirical model. Section 4 discusses the baseline results and robustness checks. Section 5 reports tests of main economic channels. Section 6 provides additional analysis and Section 7 concludes.

\section{Hypothesis Development}

Why do firms mimic their peers' trade credit policies? There are two main channels through which trade credit peer effects exist, namely peer-based information and product market competition (e.g., Decaire et al., 2019). The first channel suggests that peer influence plays a role in determining a firm's financial policy because the firm has an incentive to learn from peers' information and follow their behavior, especially when those peers are perceived as having superior information (Bikhchandani et al., 1992; Foucault and Frésard, 2014; Leary and Roberts, 2014). Mimicking is highly relevant in an environment with high information asymmetry, in which managers may be less informed and thus have stronger learning motives. To the extent that trade credit is an effective form of financing and screening in the presence of information asymmetry (e.g., Smith, 1987; Burkart and Ellingsen, 2004), it is likely to be influenced by peer-based learning. As peers offer trade credit to elicit information about buyers' default risk and creditworthiness, firms can learn such information from those peers and mimic their trade credit policies with 
similar buyers. Likewise, managers may gain private information about the opportunities to grow business through observing higher trade credit offered by peers and then take advantage of their peer-based learning by extending more trade credit themselves.

From a related perspective, managers in firms with reputational concerns may have strong incentives to follow peer firms to build a reputation, which, in turn, improves their future employment prospects and rents (Scharfstein and Stein, 1990). In the context of trade credit, suppliers may mimic their peers by extending trade receivables to buyers as a guarantee of product quality and an indicator of firm quality (Lee and Stowe, 1993; Long et al., 1993), thus maintaining their reputation as well as boosting their sales and performance. The reputation-building motive is likely to be most relevant for firms with a high level of information asymmetry and a less established reputation. Recent evidence indeed suggests that small and young firms, which typically face reputational concerns, tend to provide favorable trade credit terms to customers, especially those that are larger and more creditworthy (e.g., Klapper et al., 2012; Murfin and Njoroge, 2014). Overall, the above arguments suggest that less informed and established suppliers may have strong learning and reputation-building motives to follow their peers' trade credit policies.

The second channel, based on rivalry-based theories, suggests that competition intensity in the product market provides firms with strong incentives to mimic their peers (Lieberman and Asaba, 2006). Peer mimicking enables firms to maintain their relative position in the market, especially when dealing with aggressive actions of rivals. In the context of supplier financing, this argument is highly relevant. Fisman and Raturi (2004) show that competition promotes trade credit provision, which in turn prevents customer switching and helps suppliers maintain their market power. ${ }^{5}$ Empirically, Fabbri and Klapper (2016) show that firms use trade credit as a favorable competitive device, not only to avoid losing existing customers, but also to attract new buyers and reduce competitive pressure. ${ }^{6}$ In a highly competitive market, firms typically fight for the same customers and offering trade credit gives them an important comparative advantage over other suppliers (Barrot, 2016). This behavior in turn creates a spillover effect, which encourages other suppliers to extend more trade credit to maintain their market share, until trade credit becomes a norm in that industry. An implication of this argument is

${ }^{5}$ Although prior research argues that monopoly power facilitates trade credit (Petersen and Rajan, 1997; McMillan and Woodruff, 1999; Fisman and Raturi, 2004) argue that this view no longer holds due to the hold-up problem, which prevents buyers from making relationship-specific investments and establishing their creditworthiness.

${ }^{6}$ Suppliers that face stronger competition and typically have weaker bargaining power may provide more trade credit and offer better credit terms to customers (Giannetti et al., 2011; Klapper et al., 2012; Dass et al., 2015). 
that, in competitive markets, suppliers may mimic each other and end up offering similar trade credit terms. Survey evidence shows that trade credit terms are typically uniform within industries but vary considerably across industries (Ng et al., 1999). Overall, these arguments suggest that competitive pressure in the product market may result in peer effects in trade credit provision.

While the above discussions highlight the various benefits of trade credit mimicking, from a manager's perspective, the downside of such behavior is likely to be small, for at least two reasons. First, any unfavorable outcome resulting from mimicking only has a marginal impact on the reputation of the imitating managers, who can point to similar mistakes made by other managers, including the more informed ones (Devenow and Welch, 1996; Hirshleifer and Hong Teoh, 2003). Moreover, it is considered rational to follow peer firm behavior, as top managers' performance is often judged using relative industry benchmarks (Morck et al., 1989; Bizjak et al., 2008; Jenter and Kanaan, 2015). Overall, these arguments further explain why firms may find it beneficial to mimic peers' financing decisions.

In sum, we hypothesize that peer influence should play an important role in shaping firms' trade credit provision. Peer effects in trade credit may operate through two main economic channels, peer-based information, and product market competition.

\section{Sample Data and Methodology}

\subsection{Selection of Peers}

Following Hoberg and Phillips (2016), we use TNIC to identify product-market peer firms. According to this industry classifications method, a firm's peers are defined based on the similarity between the firm's product descriptions, as listed in its annual 10-K filings, and those of its peers. The intuition behind this approach is that managers typically identify peer firms as competitors depending on how similar or different their products are, and therefore the degree of product similarity - computed based on the use of common words that describe the products - is key to classifying industries. ${ }^{7}$

To measure the relatedness of a pair of two firms and map them into industries, the TNIC approach involves the following steps. First, a set of unique words used by firms to describe their products in the annual 10-K business descriptions is constructed. Each year, a word vector for a given firm, $V_{i}$, is developed based on the nouns and proper nouns that appear in the firm's

\footnotetext{
${ }^{7}$ We thank Hoberg and Phillips for sharing the TNIC data (http://hobergphillips.usc. edu/industryclass.htm).
} 
business descriptions. ${ }^{8}$ This vector includes $W$ elements, with $W$ being the total number of the unique words used by all firms in the sample; each element in $V_{i}$ takes on the value of either 1 or 0 , with the former (latter) indicating that the firm does (does not) use a given word. Next, for each year, a pairwise word similarity score is calculated for a pair of firms $i$ and $j$, based on the product cosine similarity between their (normalized) word vectors, $V_{i}$ and $V_{j}$. A higher cosine similarity score suggests that those two vectors have high and positive values, that is, firms $i$ and $j$ use more of the same words and thus are more likely to be membership pairs. A firm-to-firm network representation can then be constructed, based on which firms can be classified into industries using the corresponding pairwise cosine similarity scores and an appropriate minimum similarity threshold. ${ }^{9}$ This classification approach is highly flexible as it allows firms to have different competitors at different points in time, depending on how their technologies and product offerings evolve.

Overall, unlike other static industry classifications such as SIC and NAICS used in previous research (e.g., Leary and Roberts, 2014; Grennan, 2019), the approach based on TNIC yields a measure of peers that is firm-specific and dynamic. Specifically, TNIC allow each firm to have its own set of unique competitors, which varies overtime based on changes in the firm's product market descriptions and/or those of its competitors. This is an important advantage of TNIC over predefined and static industry classifications (e.g., SIC and NAICS), which tend to have fixed industry memberships and rarely reclassify firms over time, even when their product markets evolve. Another relevant advantage of using TNIC is, as detailed above, that peer firms are defined based on product descriptions rather than production processes, implying that TNIC-based peers are more likely to be exposed to common demand shocks, a strong indication of firm relatedness (Foucault and Frésard, 2014).

Empirically, recent research shows that using TNIC in identifying peer firms is highly beneficial. Indeed, TNIC are superior in explaining changes in key firm characteristics induced by competitive pressure in the product market, including profitability, sales growth, operating cash flows, advertising, R\&D activities, mergers and acquisitions, and payout policy (e.g., Hoberg and Phillips, 2010; Hoberg et al., 2014; Hoberg and Maksimovic, 2015). In sum, based on the important advantages of TNIC, we employ these classifications to identify peers in our empirical analysis. As in Cao et al. (2019), our

\footnotetext{
${ }^{8}$ Hoberg and Phillips (2016) suggest using nouns and proper nouns that do not appear more than a quarter of all product descriptions to avoid including common words. Omitted from a firm's vocabulary are common words (e.g., those employed by more than a quarter of all firms), geographical words, and names of the top 50 cities in the US and the world. A typical firm uses about 200 unique words.

${ }^{9}$ This threshold is typically pre-specified to maintain the same proportion of possible membership pairs as three-digit SIC codes. For instance, a $21.32 \%$ minimum threshold is used to create $2.05 \%$ membership pairs. A pair of firms $i$ and $j$ with a $25 \%$ similarity score are then considered to be in the same industry.
} 
identification of peers is based on ex-ante information as we construct a firm's distinct set of competitors using the TNIC data in the previous fiscal year, before the firm implements its trade credit policy. This approach also helps alleviate, to some extent, the concern about sample selection and endogeneity. Note that although we use TNIC to identify peer firms in the main analysis, we also adopt different definitions of peers based on traditional (three-digit) SIC and Fama-French industry classifications in our robustness checks (Section 4.2).

\subsection{Trade Credit Provision and Control Variables}

Following the existing literature (e.g., Petersen and Rajan, 1997; Love et al., 2007; Giannetti et al., 2011; Garcia-Appendini and Montoriol-Garriga, 2013; Chod et al., 2019), we use a conventional measure of trade credit provision, namely, accounts receivable scaled by total sales. In our robustness tests, we also consider the ratio of trade receivables to total assets along with other proxies for trade credit policies.

In terms of the control variables, we again follow previous studies and include in our baseline model several firm and peer characteristics, namely firm size, profitability (ROA), leverage, tangibility, cash, and sales growth, gross margin, and sales (e.g., Petersen and Rajan, 1997; Choi and Kim, 2005; Giannetti et al., 2011; Garcia-Appendini and Montoriol-Garriga, 2013). To calculate these variables, we retrieve company financial data from Compustat. Our sample covers all manufacturing firms (SIC codes 2000-5999), except regulated utilities (SIC codes 4800-4999). The definitions and data sources of all variables used in our analysis are provided in Appendix A.

Table 1 contains the summary statistics of our final sample of 37,502 firmyear observations. It provides details on all variables used in the analysis, firm-specific and averages for product-market peers alike. The sample period is between 1997 and 2015, for which the TNIC data used to identify peer firms are available. To alleviate the effects of outliers, we winsorize all continuous variables at the $1^{\text {st }}$ and $99^{\text {th }}$ percentiles of their distributions. The mean receivables to sales ratio is $15 \%$, with a standard deviation of $10.30 \%$. On the other hand, the average receivables to sales ratio of peer firms is $14.70 \%$, which is almost the same as the mean receivables to sales ratio of the sample firms.

\subsection{Empirical Model}

Following recent research on peer effects (e.g., Leary and Roberts, 2014; Foucault and Frésard, 2014; Grennan, 2019), we use the following model to examine the impact of peer firm behavior on a firm's trade credit policy

$$
y_{i j t}=\alpha+\beta \bar{y}_{-i j t}+\gamma^{\prime} \bar{X}_{-i j, t-1}+\lambda^{\prime} X_{i j, t-1}+\delta^{\prime} \mu_{t}+\epsilon_{i j t}
$$




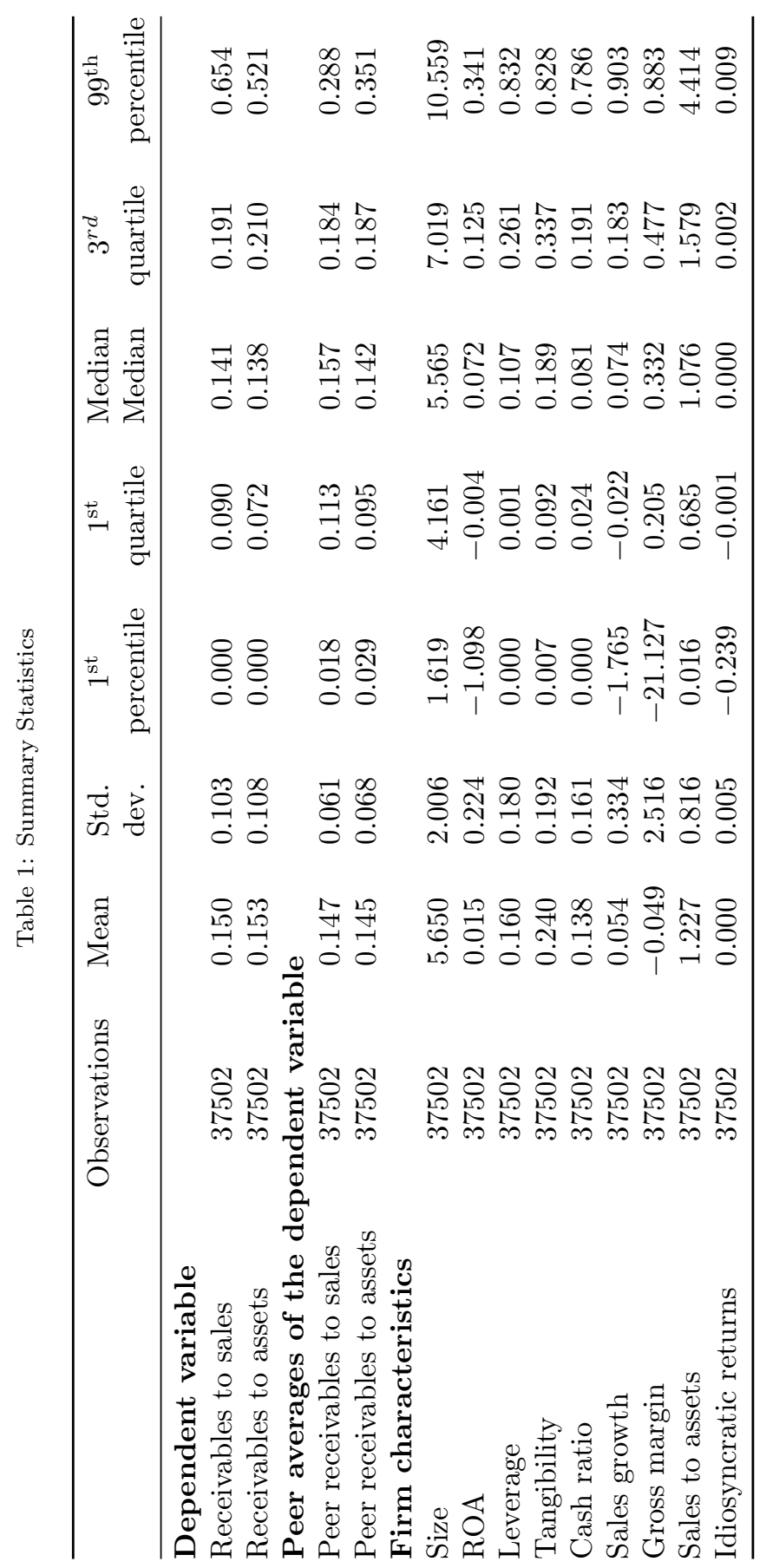




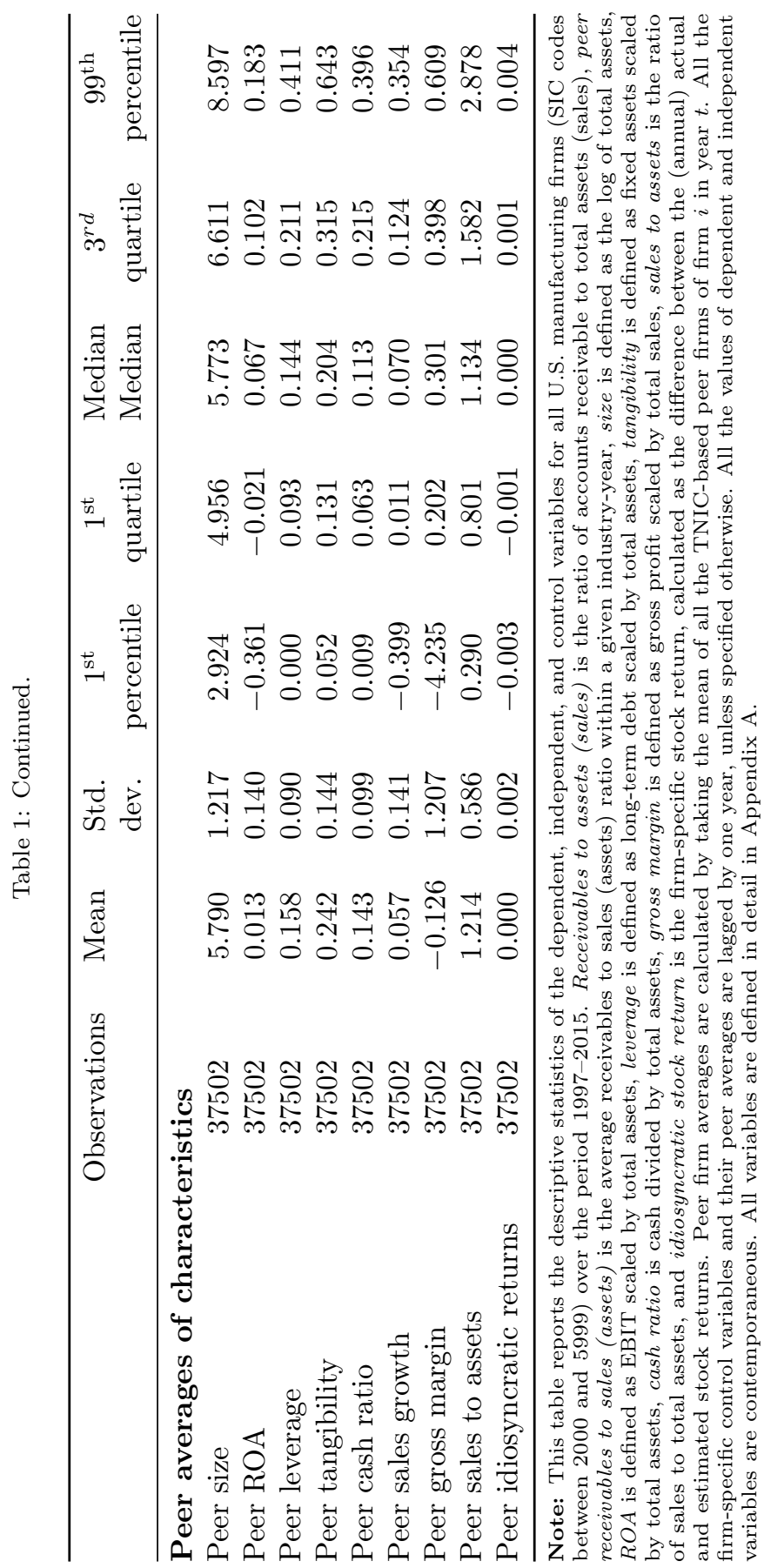


where the subscripts $i, j$, and $t$ denote firm, industry, and year, respectively; $y_{i, j, t}$ is the dependent variable capturing firm $i$ 's trade credit provision; $\bar{y}_{-i j t}$ is the average trade receivables of TNIC-based peers, excluding firm $i ; X_{i j, t-1}$

are 1-year lagged control variables; $\bar{X}_{-i j, t-1}$ are 1-year lagged averages of the same control variables for peer firms, excluding firm $i$ (i.e., the peer averages); $\mu_{t}$ is year fixed effects; and $\epsilon_{i j t}$ is the error term. We include the year fixed effects to control for potential changes in trade credit provision over time, including periods of crises (Love et al., 2007; Garcia-Appendini and MontoriolGarriga, 2013; Gonçalves et al., 2018). In our regression analysis, we are mainly interested in the two coefficients $\beta$ and $\gamma^{\prime}$, which capture peer effects through peer firms' actions and characteristics, respectively.

\subsection{Identification Strategy and 2SLS Regression Approach}

\subsubsection{Instrumental Variable and 2SLS Regressions}

As briefly mentioned, using OLS to estimate Model (1) may lead to a biased estimate of peer effects due to the reflection problem (Manski, 1993). This problem is a specific type of endogeneity that arises when one regresses the outcome variable on its group averages such that evidence of a correlation between the two variables does not imply causality (Manski, 1993; Angrist, 2014). In the context of our analysis, the regression of an individual firm's trade credit provision on its peer averages may be a spurious one due to the endogenous selection of firms into peer groups (Leary and Roberts, 2014). Alternatively, there may be common omitted factors that influence both the firm's and its peers' trade credit decisions, leading to omitted variable bias. Overall, the reflection problem poses a major challenge to research studying peer effects in corporate finance (e.g., Manski, 1993; Leary and Roberts, 2014; Grennan, 2019). Nevertheless, this endogeneity concern can be alleviated by exploiting an external shock, acting as an instrumental variable that is correlated with the endogenous explanatory variable of interest, peer accounts receivable (i.e., the relevance restriction), but that is orthogonal to any omitted characteristics (i.e., the exclusion restriction). The latter condition also requires that the instrument must be uncorrelated with the dependent variable, firms' trade receivables, by means of any other channel, except through the endogenous variable itself.

As suggested by Leary and Roberts (2014), for identification purposes, we employ peer idiosyncratic stock returns as a possible exogenous (equity) shock to address the above endogeneity concerns. This variable is likely to satisfy both the relevance and exclusion conditions of a valid instrument for peer effects, for the following reasons. First, in terms of the relevance restriction, previous research shows that stock returns are significantly related to a firm's financing (e.g., Myers, 1977; Myers, 1984; Baker and Wurgler, 2002; Welch, 
2004) and investment decisions (e.g., Lamont, 2000; Cooper et al., 2008; Liu et al., 2009; Titman et al., 2004). To the extent that trade credit is one of the most important sources of financing for customers (Brick and Fung, 1984; Petersen and Rajan, 1997; Mateut et al., 2006) as well as a relevant form of (short-term) investment for suppliers (e.g., Abdulla et al., 2020), it should be highly correlated with stock returns. Empirically, previous evidence indeed documents a strong association between trade credit and stock returns (Hill et al., 2012; Goto et al., 2015; Albuquerque et al., 2013). Overall, both theory and evidence indicate that idiosyncratic stock returns are likely to satisfy the relevance condition of a valid instrument for peer effects.

Regarding the exclusion restriction, there are at least three reasons to expect peer idiosyncratic stock returns to satisfy this restriction (Leary and Roberts, 2014). First, because idiosyncratic stock returns are estimated from traditional asset pricing models after removing market and industry-wide variation in total returns, they capture the remaining and plausibly exogenous variation in peer firm-specific stock returns, rather than common factors. Moreover, as equity shocks to individual firms, idiosyncratic stock returns are generally uncorrelated with each other within a peer group, serially uncorrelated, or serially crossuncorrelated. Hence, these shocks cannot forecast future shocks for themselves or other firms. Peer firm equity shocks are likely to be uncorrelated with firm-specific characteristics, while they are less likely to be affected by firms' manipulation than conventional determinants of corporate financial decisions. Overall, these important properties suggest that peer idiosyncratic stock returns are a plausibly relevant and exogenous instrument. Hence, as in recent studies of peer effects (e.g., Leary and Roberts, 2014; Grennan, 2019), we employ this equity shock as a source of exogenous variation in peer trade credit policy.

To calculate the instrument, peer idiosyncratic stock returns, we first estimate the expected stock return using the Fama and French (1993) threefactor model, as follows:

$$
r_{i j t}=\alpha_{i}+\beta_{1 i}\left(r m_{t}-r f_{t}\right)+\beta_{2 i} S M B_{t}+\beta_{3 i} H M L_{t}+\eta_{i j t}
$$

where $r_{i j t}$ captures the stock return of firm $i, \quad$ in industry $j$, and over month $t$. The three factors in the model are the excess market return $\left(r m_{t}-r f_{t}\right)$, the small minus big portfolio $\left(S M B_{t}\right)$ returns (size factor), and the high minus low $\left(H M L_{t}\right)$ portfolio returns (value factor). We obtain stock returns from the Center for Research in Security Prices (CRSP) and data on the Fama and French factors (i.e., market returns, $S M B$, and $H M L$ ) from Kenneth French's database. $^{10}$ We estimate expected stock returns by using a monthly rolling regression approach to estimate Equation (2). As Leary and Roberts (2014) and Seo (2017), we require at least 24-month historical returns for each firm

\footnotetext{
${ }^{10}$ The data is available at http://mba.tuck.dartmouth.edu/pages/faculty/ken.french/ data_library.html.
} 
and use five years of data in measuring this variable. Using the estimated coefficients from Equation (2), we calculate the expected stock returns as follows:

$$
\hat{r}_{i j t}=\hat{\alpha}_{i}+\hat{\beta}_{1 i}\left(r m_{t}-r f_{t}\right)+\hat{\beta}_{2 i} S M B_{t}+\hat{\beta}_{3 i} H M L_{t}
$$

We then convert the monthly returns data into annual returns to match with our firm-year data. In the next step, we calculate idiosyncratic stock returns as the difference between the observed and expected stock returns, as follows:

$$
I_{d i o_{-i j t}}=r_{i j t}-\hat{r}_{i j t},
$$

We compute our instrument, Idio-ij,t-1, by taking 1-year lagged average peer idiosyncratic stock returns using TNIC-based peers, where $j$ represents the TNIC peers of firm $i$.

Finally, we use $I d i o_{-i j, t-1}$ as an instrument for peer influence in our 2SLS regressions. Our approach involves estimating Equations (5) and (6) in two stages, respectively:

$$
\begin{aligned}
\bar{y}_{-i j t} & =\alpha+\beta_{1} I_{d i o_{-i j, t-1}}+\beta_{2} \bar{X}_{-i j, t-1}+\beta_{3} X_{i j, t-1}+\beta_{4} \mu_{t}+\xi_{i j t} \\
y_{i, j, t} & =\alpha+\beta \hat{\bar{y}}_{-i j t}+\gamma^{\prime} \bar{X}_{-i j, t-1}+\lambda^{\prime} X_{i j, t-1}+\delta^{\prime} \mu_{t}+\epsilon_{i j t}
\end{aligned}
$$

In the first stage, we estimate the reduced-form model (Equation (5)), where we regress the endogenous variable, peer average trade receivables, on the instrument, Idio $-i j, t-1$, as well as the controls, namely, the firm-specific characteristics, average peer characteristics, and year fixed effects. We then obtain the fitted values for peer average trade credit, $\hat{\bar{y}}_{-i, j, t}$, and use them in the second stage (Equation (6)) to estimate the peer effects, $\beta$, in trade credit policy.

\subsubsection{Properties of Instrumental Variable}

One remaining concern about the instrument used in our 2SLS regressions, peer idiosyncratic stock returns, is that it may still be correlated with omitted or (mismeasured) common factors, with the latter serving as the determinants of trade credit provision (Leary and Roberts, 2014). To address this concern, we regress our main instrument on both the contemporaneous and 1-year ahead firm-level controls. This regression analysis allows us to examine whether the instrument used contains any information about the present or future firm characteristics. Leary and Roberts (2014) argue that a correlation between peer idiosyncratic stock returns and the firm characteristics is not problematic per se since we already control for these firm characteristics in our main model. However, any large economic associations between these variables may reflect the degree to which the instrument is correlated with unobservable factors as well as the extent to which some of the common variation has not been effectively removed from total returns. Hence, it is important to study the magnitude of the impact of the firm-specific determinants of trade receivables on the instrument. 
Table 2: Estimating Idiosyncratic Stock Returns

\begin{tabular}{|c|c|c|}
\hline & \multicolumn{2}{|c|}{ Peer average idiosyncratic stock returns } \\
\hline & $\begin{array}{c}\text { Contemporaneous } \\
\text { independent } \\
\text { variables }\end{array}$ & $\begin{array}{l}\text { 1-year ahead } \\
\text { independent } \\
\text { variables }\end{array}$ \\
\hline \multirow[t]{2}{*}{ Size } & 0.000 & -0.000 \\
\hline & $(0.59)$ & $(-0.20)$ \\
\hline \multirow[t]{2}{*}{$\mathrm{ROA}$} & 0.000 & 0.000 \\
\hline & $(0.53)$ & $(0.43)$ \\
\hline \multirow[t]{2}{*}{ Leverage } & 0.000 & 0.000 \\
\hline & $(0.86)$ & $(0.73)$ \\
\hline \multirow[t]{2}{*}{ Tangibility } & 0.000 & 0.000 \\
\hline & $(0.68)$ & $(0.94)$ \\
\hline \multirow[t]{2}{*}{ Cash ratio } & -0.000 & -0.000 \\
\hline & $(-0.13)$ & $(-0.54)$ \\
\hline \multirow[t]{2}{*}{ Sales growth } & -0.000 & 0.000 \\
\hline & $(-0.82)$ & $(0.01)$ \\
\hline \multirow[t]{2}{*}{ Gross margin } & -0.000 & -0.000 \\
\hline & $(-0.94)$ & $(-1.30)$ \\
\hline \multirow[t]{2}{*}{ Sales to assets } & 0.000 & 0.000 \\
\hline & $(1.19)$ & $(0.86)$ \\
\hline \multirow[t]{2}{*}{ Constant } & $-0.001^{* * *}$ & $-0.001^{* * *}$ \\
\hline & $(-10.13)$ & $(-10.46)$ \\
\hline Observations & 37,502 & 37,501 \\
\hline Peer averages of firm characteristics & Yes & Yes \\
\hline Year fixed effects & Yes & Yes \\
\hline $\operatorname{Adj} R^{2}$ & 0.576 & 0.575 \\
\hline$F$-stat & 1500 & 1496 \\
\hline
\end{tabular}

Note: The sample consists of all U.S. manufacturing firms (SIC codes between 2000 and 5999) over the period 1997-2015. The main dependent variable is peer idiosyncratic stock returns. All the firm-specific controls and their peer averages are either contemporaneous (Column (1)) or 1-year lead (Column (2)). Size is defined as the log of total assets, $R O A$ is defined as EBIT scaled by total assets, leverage is defined as long-term debt scaled by total assets, tangibility is defined as fixed assets scaled by total assets, cash ratio is cash divided by total assets, gross margin is defined as gross profit scaled by total assets, and sales to assets is the ratio of sales to total assets. Peer firm averages are calculated by taking the mean of all the TNIC-based peer firms of firm $i$ in year $t$. All variables are defined in detail in Appendix A. Standard errors reported in parentheses are clustered at the firm level. ***, and *** denote statistical significance at the $10 \%, 5 \%$, and $1 \%$ levels, respectively.

Table 2 reports the results from our analysis of the properties of the instrumental variable, where we regress peer idiosyncratic stock returns on the firm characteristics. In both specifications, using either contemporaneous or 1-year lead values, none of the firm characteristics is correlated with the instrument. Moreover, the economic magnitude of all firm characteristics is 
very low, suggesting that peer idiosyncratic stock returns do not contain any significant information about the present or future observable determinants of firms' trade receivables. These results provide further assurance about the validity of the instrument used. Note that although we adopt this instrument throughout our main analysis, in a robustness check, we consider an alternative instrument and show that our main inference is insensitive to the choice of the instrumental variable.

\section{Main Results}

\subsection{Peer Effects in Trade Credit Provision}

To investigate whether trade credit provision is affected by peer firm behavior, we adopt the 2SLS regression approach, as detailed above. Table 3 reports the results from both the first and second stages of those regressions. Columns (1) and (2) present the estimates of our baseline regression of receivables to sales on the main independent variable, peer receivables to sales, while controlling for firm characteristics, peer averages, and year fixed effects. In the first-stage regression (Column (1)), we find that the coefficient on the instrument, peer idiosyncratic stock returns, is significant and positive, indicating that the average equity shock is strongly and positively related to average peer trade receivables. This result is consistent with prior evidence that investment is positively correlated with stock returns (e.g., Lamont, 2000; Liu et al., 2009). Note that the $F$-statistic from our diagnostic test is quite large, suggesting that the instrument is likely to be valid. Importantly, in the second-stage regression (Column $(2)$ ), the coefficient on peer receivables to sales (0.957) is positive and statistically significant at the $1 \%$ level, providing strong evidence of peer influence on trade credit policy. In terms of the economic magnitude of peer effects, one standard deviation (0.061) increase in peer receivables to sales is associated with an increase of 0.058 in trade receivables, which is equivalent to a $39 \%$ increase relative to its mean. These findings collectively indicate that peer effects in trade credit provision are both statistically significant and practically important.

In the remainder of Table 3, we estimate alternative model specifications to study the robustness of our results. In columns (3) and (4), we include industry fixed effects, based on the Fama-French 49 industry classifications, to further control for variation in trade credit provision across industries (e.g., Giannetti et al., 2011). In columns (5) and (6), we estimate an even more stringent specification with year fixed effects as well as firm fixed effects; the latter is included to control for time-invariant unobserved factors. The results in columns (3) to (6) are qualitatively similar to those reported in columns (1) and (2), suggesting that our main inference is unlikely to be affected by heterogeneity bias. Overall, our baseline regression analysis shows that firms mimic their peers' trade receivables, which is consistent with our main hypothesis. 


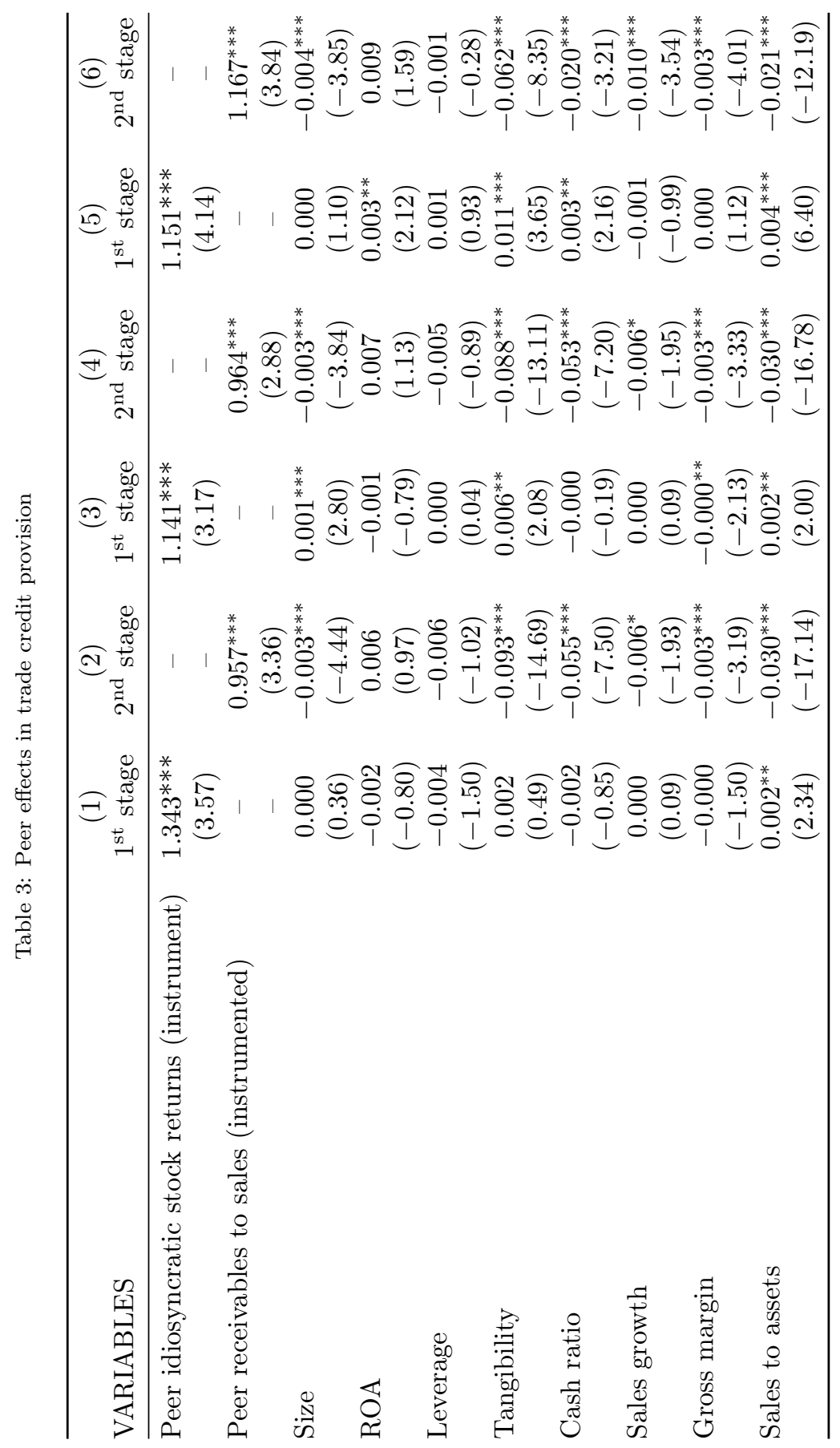




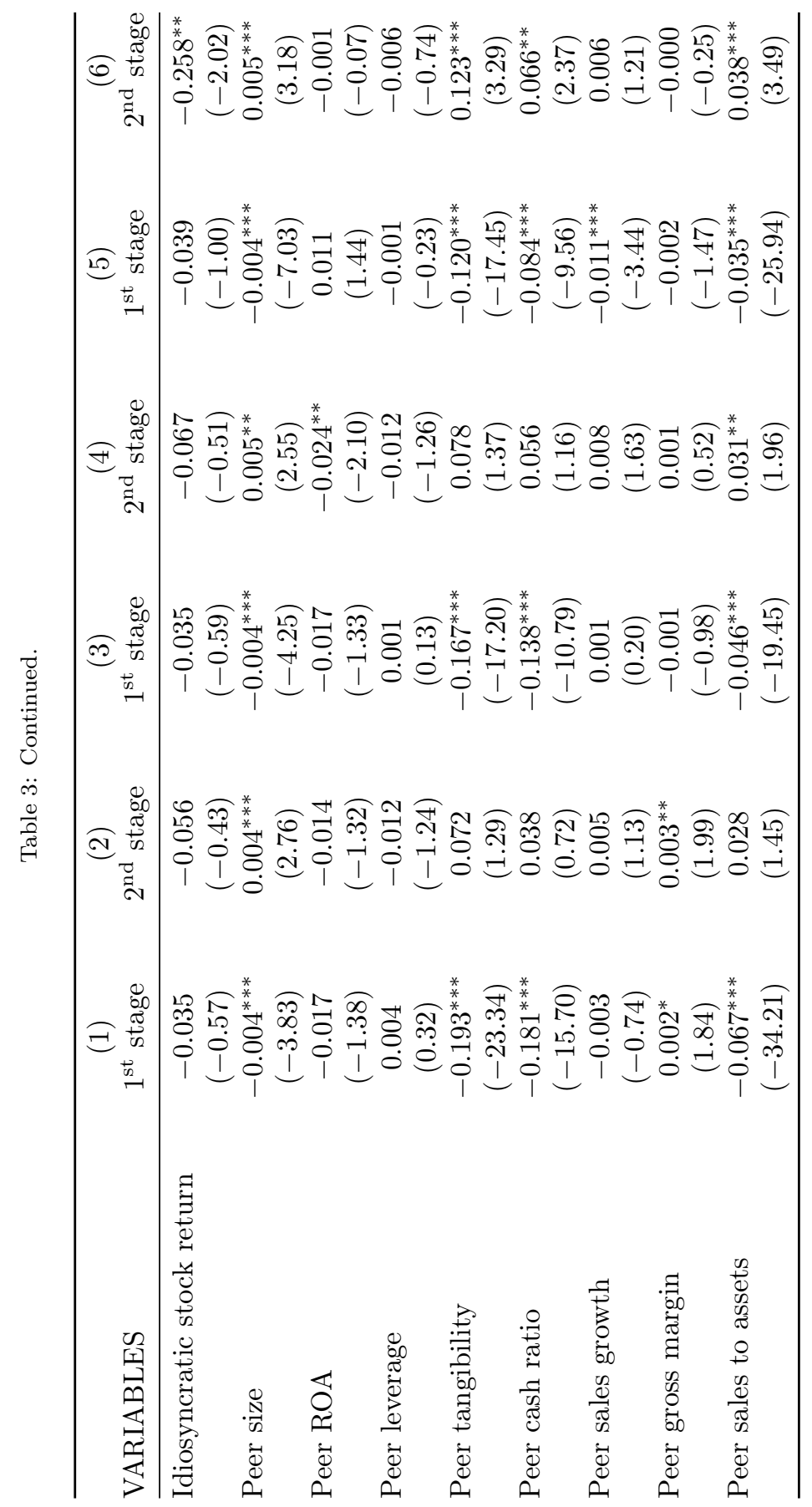




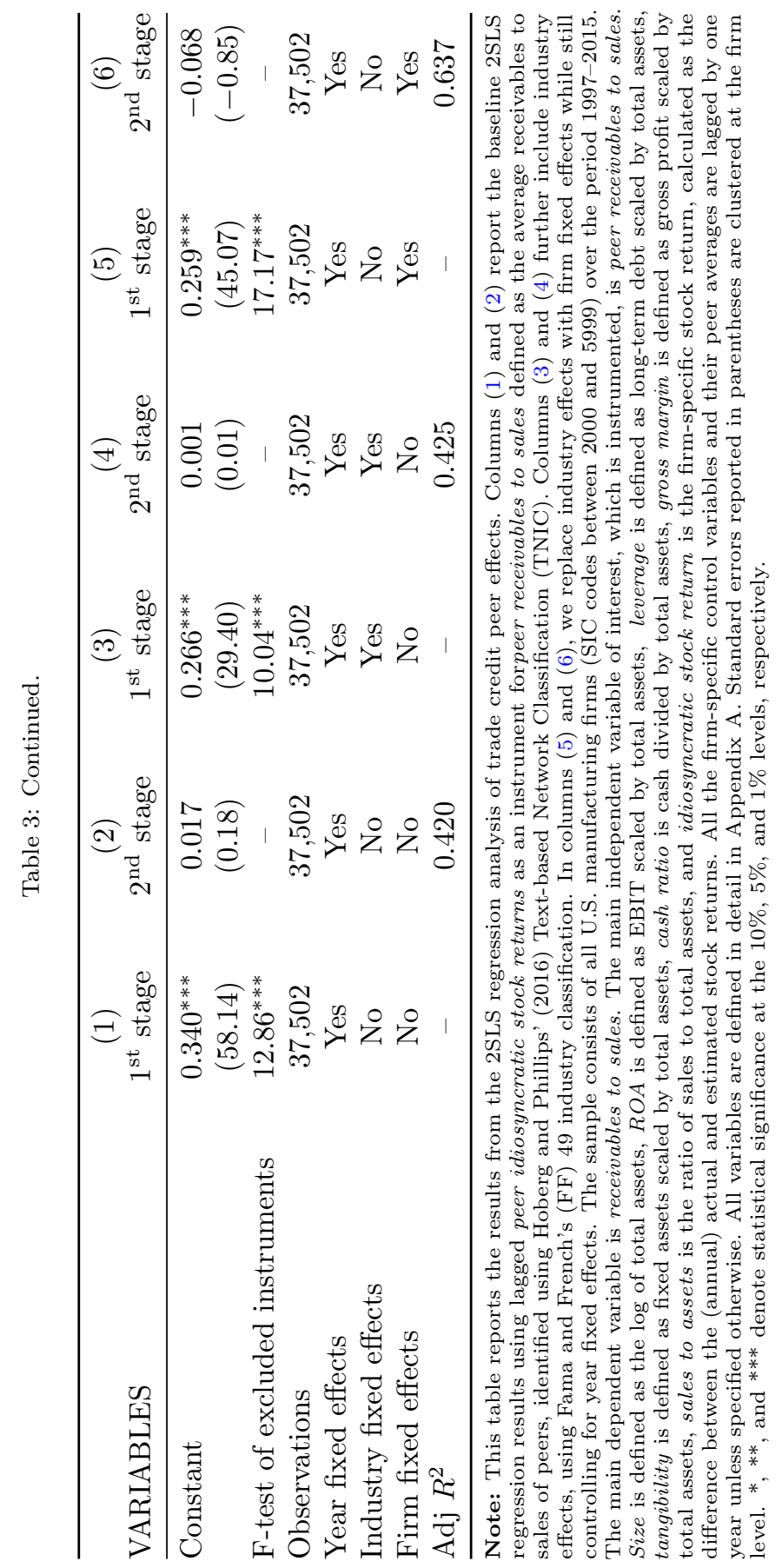


The results regarding firm-level controls are broadly in line with prior theoretical expectations and evidence (e.g., Petersen and Rajan, 1997; Giannetti et al., 2011; Garcia-Appendini and Montoriol-Garriga, 2013; El Ghoul and Zheng, 2016). In the second-stage results (columns (2), (4), and (6)) in Table 3, the coefficients on most of the firm-specific determinants of trade receivables are statistically significant, except $R O A$, leverage, and $i d$ iosyncratic stock returns. Specifically, tangibility is negatively and significantly related to receivables to sales at the $1 \%$ level, consistent with prior evidence (e.g., Giannetti et al., 2011) and the substitution effect between investing in fixed assets and accounts receivable (Abdulla et al., 2020). The results regarding size show that smaller firms tend to offer more trade credit than large firms, consistent with El El Ghoul and Zheng (2016). Collectively, the results regarding tangibility and size suggest that more creditworthy suppliers, namely larger firms with more tangible assets, do not extend more trade credit than those with the opposite characteristics, which is inconsistent with the redistribution view (e.g., Meltzer, 1960; Rauch, 1999; Scharfstein and Stein, 1990; Nilsen, 2002). However, these results seem to support the notion that firms with a less established reputation, such as small firms, tend to extend more trade credit for commercial and operational motives (Lee and Stowe, 1993; Long et al., 1993). The coefficients on the cash ratio, sales growth, gross margin, and sales to assets, are negative and broadly significant, consistent with the idea that firms with less cash, low profit margins, and low sales growth tend to supply more trade credit. Again, these results are consistent with the argument that firms in a weaker financial position tend to extend more trade credit to maintain sales (Petersen and Rajan, 1997; El Ghoul and Zheng, 2016).

We next examine the results regarding the (average) peer controls. Columns (2), (4), and (6) show that the coefficients on most of the peer characteristics are not consistently significant across different model specifications. The only exception is peer firm size, which has a statistically significant but otherwise economically small impact on trade receivables. As in Leary and Roberts (2014), we interpret these findings as evidence of trade credit peer effects operating mainly through peer firms' actions rather than their characteristics. Overall, our results persist in various specifications, again providing strong empirical support for the central hypothesis that peer firm behavior significantly influences trade credit policy.

\subsection{Sensitivity Tests}

\subsubsection{Alternative Measures of Trade Credit and Peer Composition}

In Table 4, we test the robustness of our results to alternative measures of trade credit provision as well as alternative definitions of peers. In Column (1), 


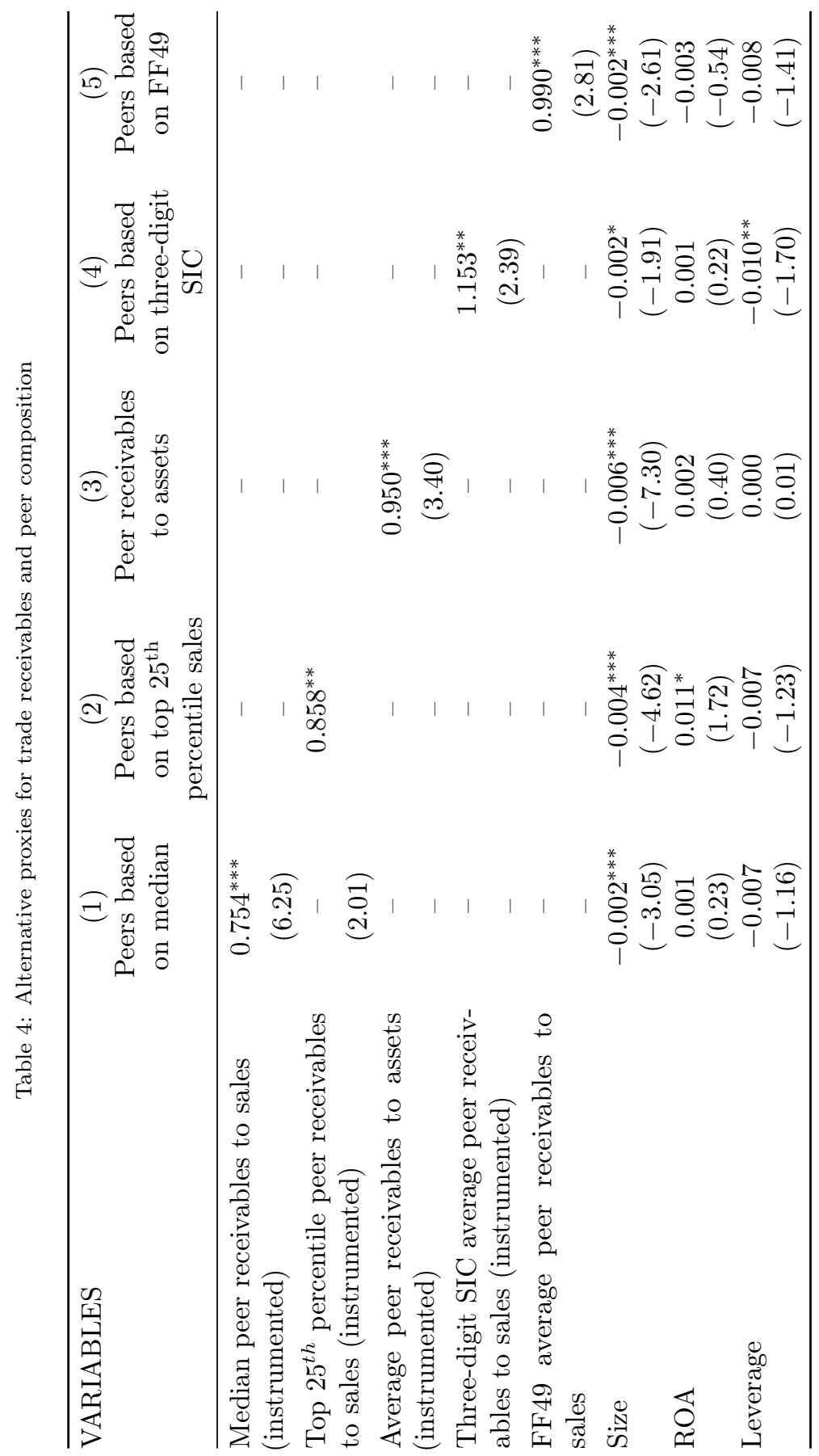




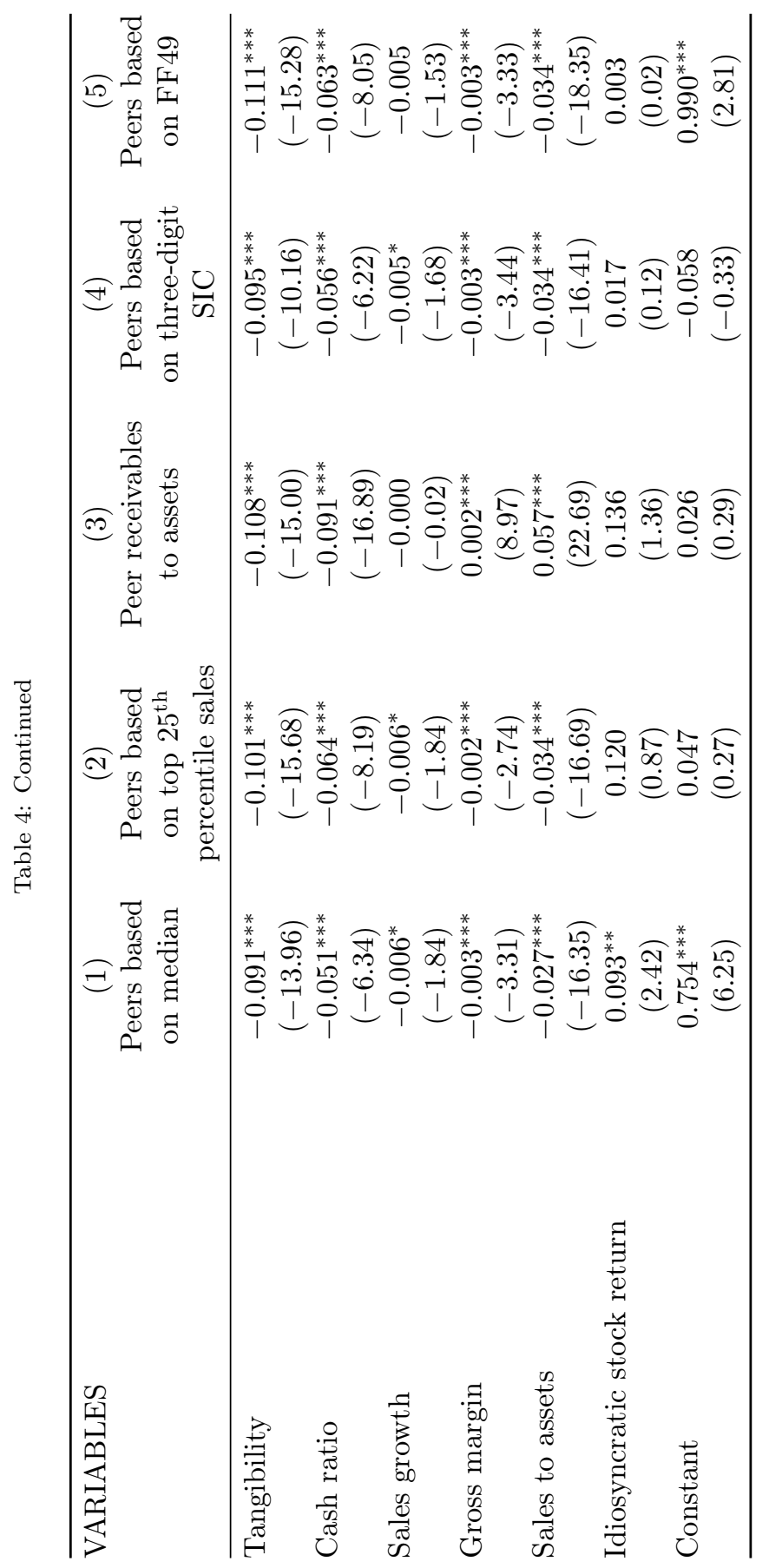




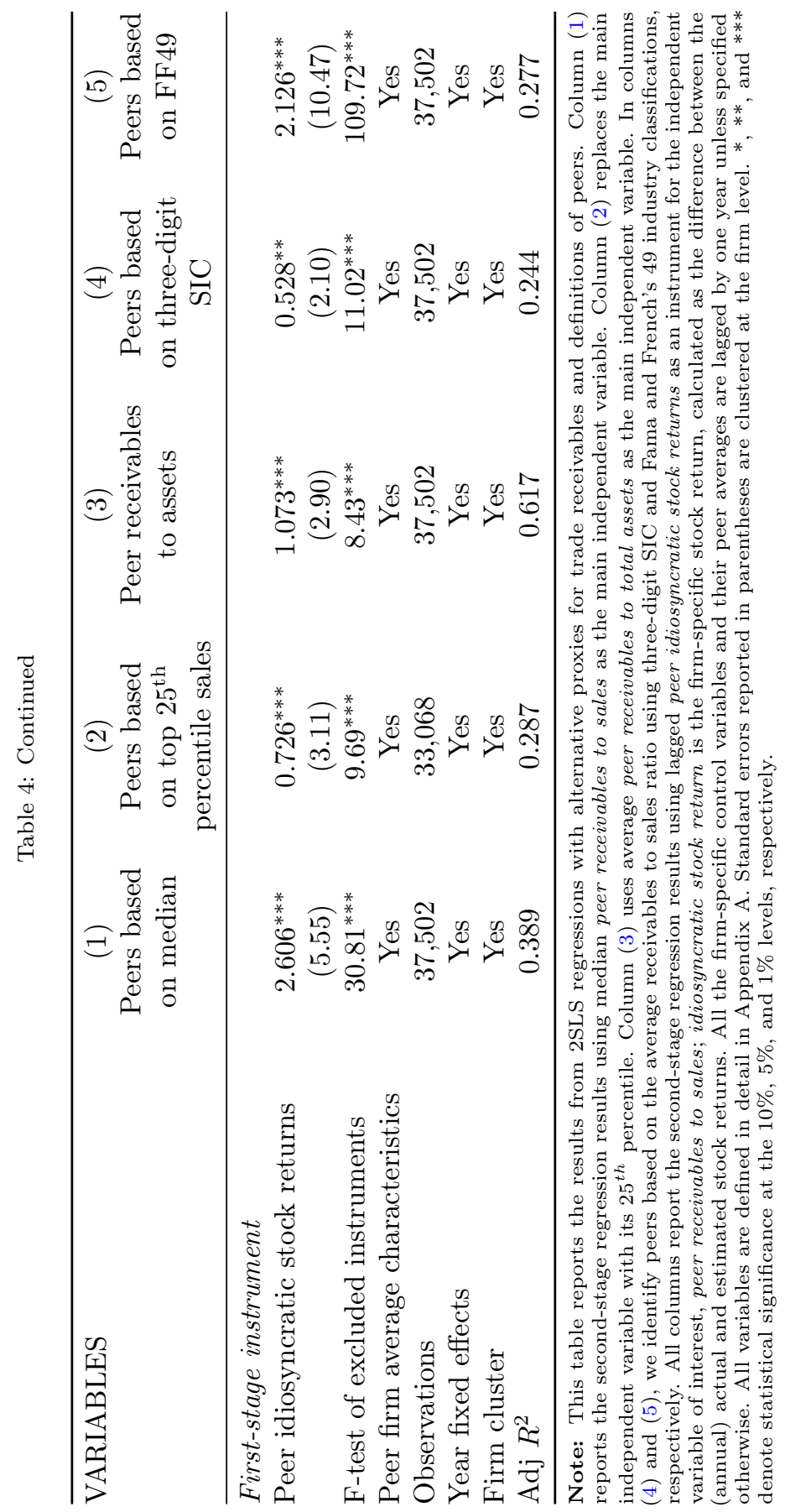


we use the median peer receivables to sales instead of the mean peer receivables to sales as our measure of trade receivables and rerun our baseline regression. In Column (2), rather than considering all peer firms, we focus on a smaller group of top firms in the industry. The rationale behind this test is that these top peers may set the standards for other firms in the industry to follow, and so their trade credit policy is more important. To perform this test, we replace the average accounts receivable of all peer firms with the average trade receivables of peers in the top $25^{\text {th }}$ percentile in each industry-year based on total sales. Next, following previous studies (Molina and Preve, 2009; El Ghoul and Zheng, 2016), we consider an alternative measure of trade credit provision based on a different scaling variable, namely receivables to assets rather than receivables to sales. In Column (3), we recalculate our dependent and main independent variables (average peer receivables) using this measure and rerun our regression. The results across columns (1)-(3) continue to show a significant and positive relationship between firm trade receivables and peer influence at the $1 \%$ level, suggesting that our main finding is robust to alternative definitions of trade credit.

In the next analysis, we examine whether our inference is sensitive to alternative peer definitions. In Column (4) of Table 4, we follow Leary and Roberts (2014) and use three-digit SIC codes rather than TNIC to identify peer firms. In Column (5), we define peers based on the Fama and French 49 industry classifications, consistent with Dougal et al. (2015) and Billett et al. (2019). The results in both columns (4) and (5) show that our key independent variable, peer receivables, continues to exert a positive and significant effect on firm trade credit policy at the $1 \%$ level. Overall, the results from various tests in Table 4 show that our main finding is robust to alternative measures of trade receivables and definitions of peer firms.

\subsubsection{Alternative Instrumental Variables}

To further alleviate endogeneity concerns and establish the robustness of our inference, we consider alternative definitions of the instrumental variable. First, we use the capital asset pricing model (CAPM) instead of the Fama and French three-factor model to calculate idiosyncratic stock returns in Equation (2). We further use the Carhart (1997) four-factor model and an augmented market model to estimate this instrument. Our augmented market model extends the CAPM by additionally controlling for the excess return on an equal-weighted industry portfolio based on Fama and French's 49 industry classification and excluding firm $i$ 's return (Leary and Roberts, 2014). We add this industry factor to remove variations in returns that are common across firms in the same peer group. Columns (1) to (3) of Table 5 report the results from the 2SLS regressions using those alternative approaches to estimate idiosyncratic stock returns. Across all models, we find that trade receivables remain signifi- 


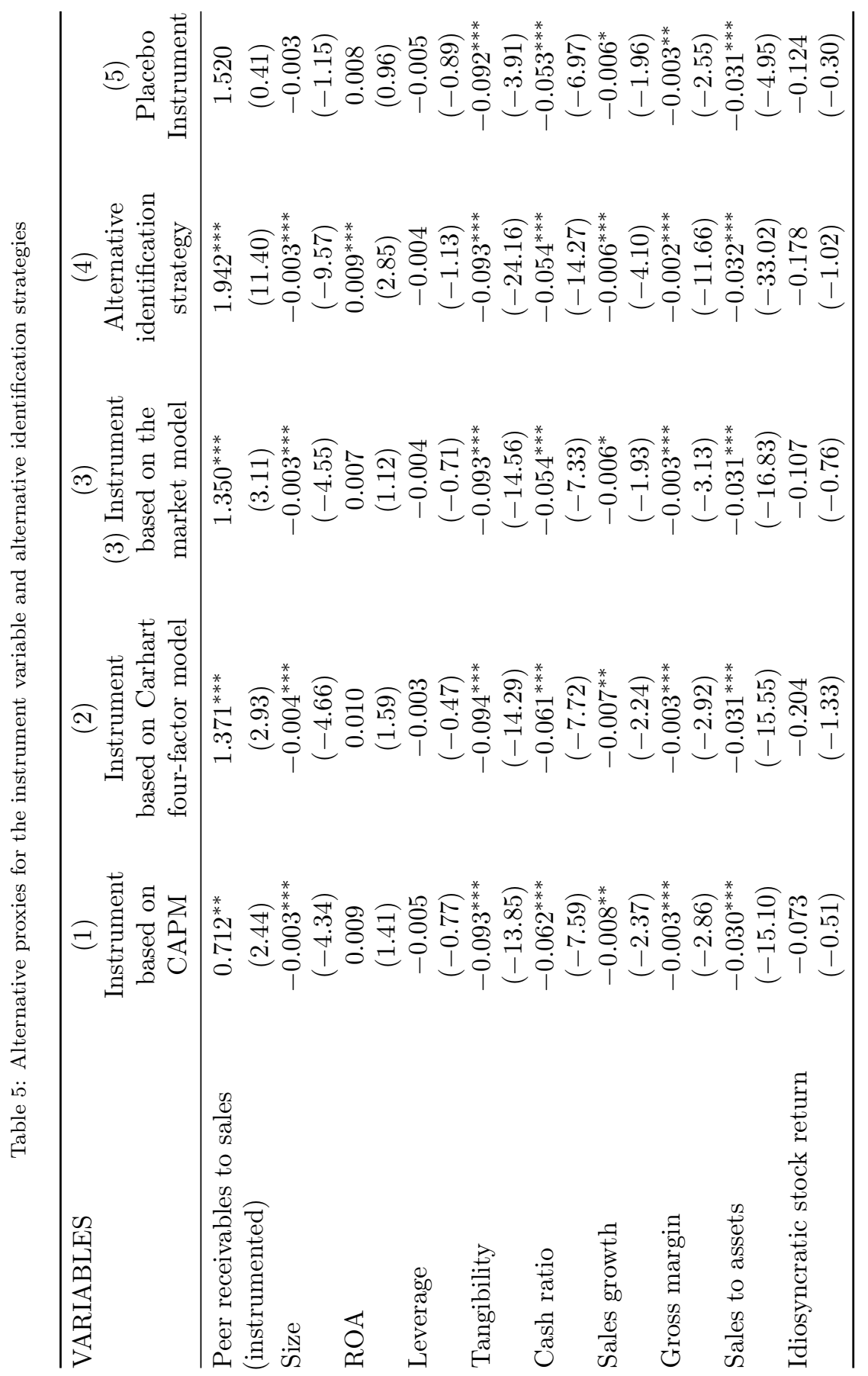




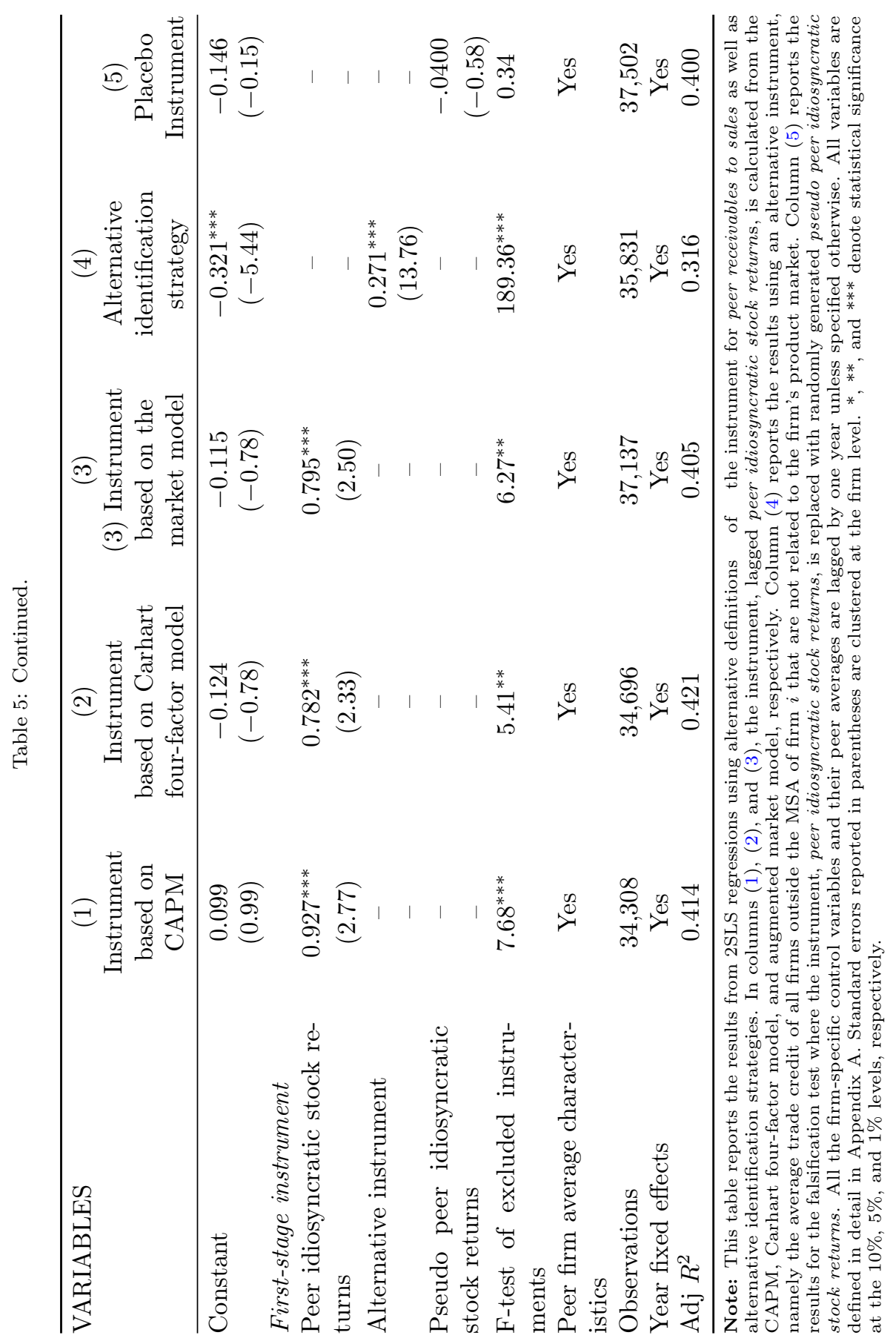


cantly and positively related to peer firm behavior, consistent with our main finding.

Next, inspired by Bustamante and Frésard (2019) recent identification strategy, we develop an instrument by exploiting both the product market and local commonality. First, we define industry (product market) peers as those in the same TNIC as before and local peers as those headquartered in the same Metropolitan Statistical Area (hereafter MSA). To construct the instrument, for each firm $i$, we consider all firms headquartered in the same MSA as the non-local TNIC peers of firm $i$. Next, we drop from this group firms in the same industry, based on the Fama-French 12 industry classifications, to cut out the direct link between the firm and its non-local industry peers. Then, we further eliminate from the remaining group all the firms that are themselves TNIC peers of any other firm, headquartered in the firm $i$ 's MSA. This step removes the indirect connections between firm $i$ and other related firms in the MSA of non-local TNIC peers. Lastly, we compute our instrumental variable as the equally-weighted average trade receivables of all the remaining (unrelated) firms located in the non-local TNIC peers' MSAs and use it as an instrument for the average trade credit of TNIC based peers of firm $i$. As in Bustamante and Frésard (2019), we argue that the instrument based on the average trade receivables of those unrelated (non-local) firms is correlated to peer firms' trade receivables (i.e., the relevance restriction) through local commonality. However, this instrument is plausibly exogenous (i.e., the exclusion restriction) because it is not directly related to the firm $i$ 's trade receivables, other than through peer influence. In Column (4) of Table 5, we report the 2SLS regression results using the alternative instrumental variable. In the first-stage regression, we find that this new instrument is significantly correlated with our main dependent variable, peer receivables to sales. Importantly, in the second stage, the coefficient on peer receivables is positive and significant at the $1 \%$ level, consistent with our main finding.

To further allay another endogeneity concern that our main results may be driven by unobserved shocks, we run a falsification test. Specifically, we replace our main instrumental variable, peer idiosyncratic stock returns, with a pseudo instrument by generating and assigning random values to the latter variable. In Column (5) of Table 5, we report the 2SLS regression results based on the pseudo peer idiosyncratic stock returns. The first-stage regression reveals that the pseudo instrument does not pass the test for instrument validity as it is not significantly associated with the explanatory variable of interest, peer receivables. More importantly, in the second-stage regression, we observe an insignificant coefficient on peer receivables. If unobserved shocks exist and affect our statistical inference, the coefficient on peer firm behavior in our placebo test would still be significant. The fact that this is not the case suggests that our main finding is unlikely to be driven by unobserved shocks. 


\section{Tests of Channels}

As discussed earlier, there are two primary motivations for firms to mimic one another's trade credit policy. The information-based channel argues that firms follow peers due to learning and reputation-building motives, while rivalry-based models suggest that product market competitive pressures force firms to mimic each other (Lieberman and Asaba, 2006). In this section, we perform direct tests of the channels through which peer effects in trade credit provision operate.

\subsection{Role of Peer-Based Information}

We first examine the role of the information channel in driving trade credit peer effects. If this channel is at work, we would expect peer effects to be more pronounced among firms that suffer from greater asymmetric information and hence have stronger incentives to learn from their peers. To examine this conjecture, we partition our data into subsamples of firms with high and low information asymmetry based on two commonly used measures of asymmetric information, namely analyst coverage and analyst forecast dispersion (e.g., Healy and Palepu, 2001). Firms with a limited number of analysts covering and those with greater analyst forecast dispersion are considered to have a high degree of information asymmetry.

Columns (1)-(4) of Table 6 report the 2SLS regression results from our analysis. In columns (1) and (2), we classify a firm as having high (low) information asymmetry if the number of analysts covering the firm is below (above) the annual industry median analyst coverage. In columns (3) and (4), firms with high (low) information asymmetry are defined as those with above (below) annual industry median analyst forecast dispersion. We then test whether those firms with high information asymmetry and hence greater learning motives exhibit more peer mimicking behavior than those with low information asymmetry. In our cross-sectional analysis, we calculate the independent variable of interest, peer receivables to sales, and the peer averages of firm characteristics using the whole sample. ${ }^{11}$ Columns (1) and (3) reveal that peer influence is statistically insignificant among firms with high information asymmetry. In contrast, the results in columns (2) and (4) show that firms with low information asymmetry mimic the trade credit policy of the average peer firm in the sample. These results are inconsistent with the argument based on learning motives.

\footnotetext{
${ }^{11}$ In (untabulated) analysis, we focus on a more restrictive setting and calculate peer receivables to sales and peer averages of firm characteristics using the subsample of firms with low information asymmetry. The idea behind this analysis is to examine whether firms with high information asymmetry (the less informed) mimic those peers with low information asymmetry (the more informed). The results are qualitatively similar.
} 


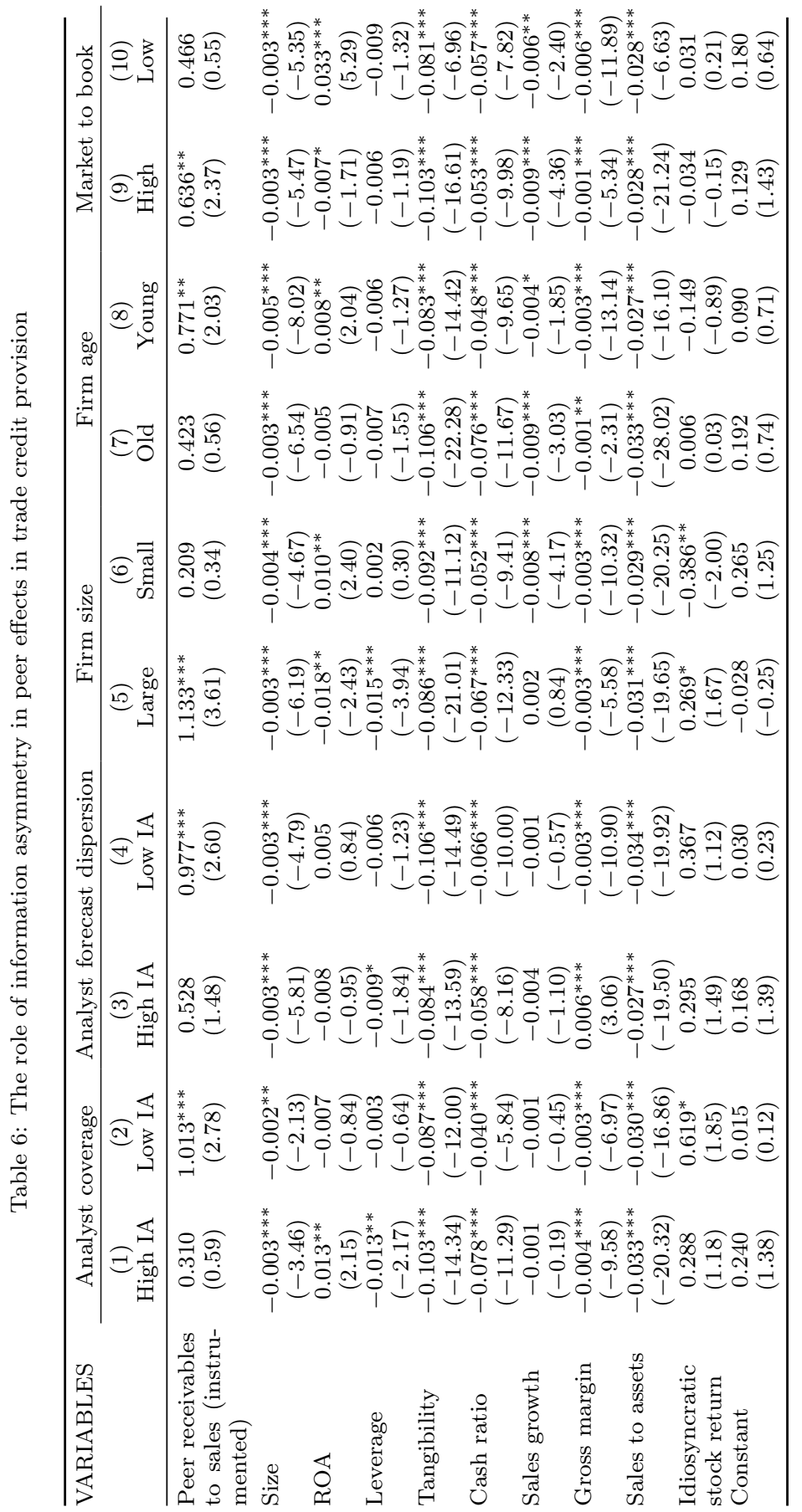




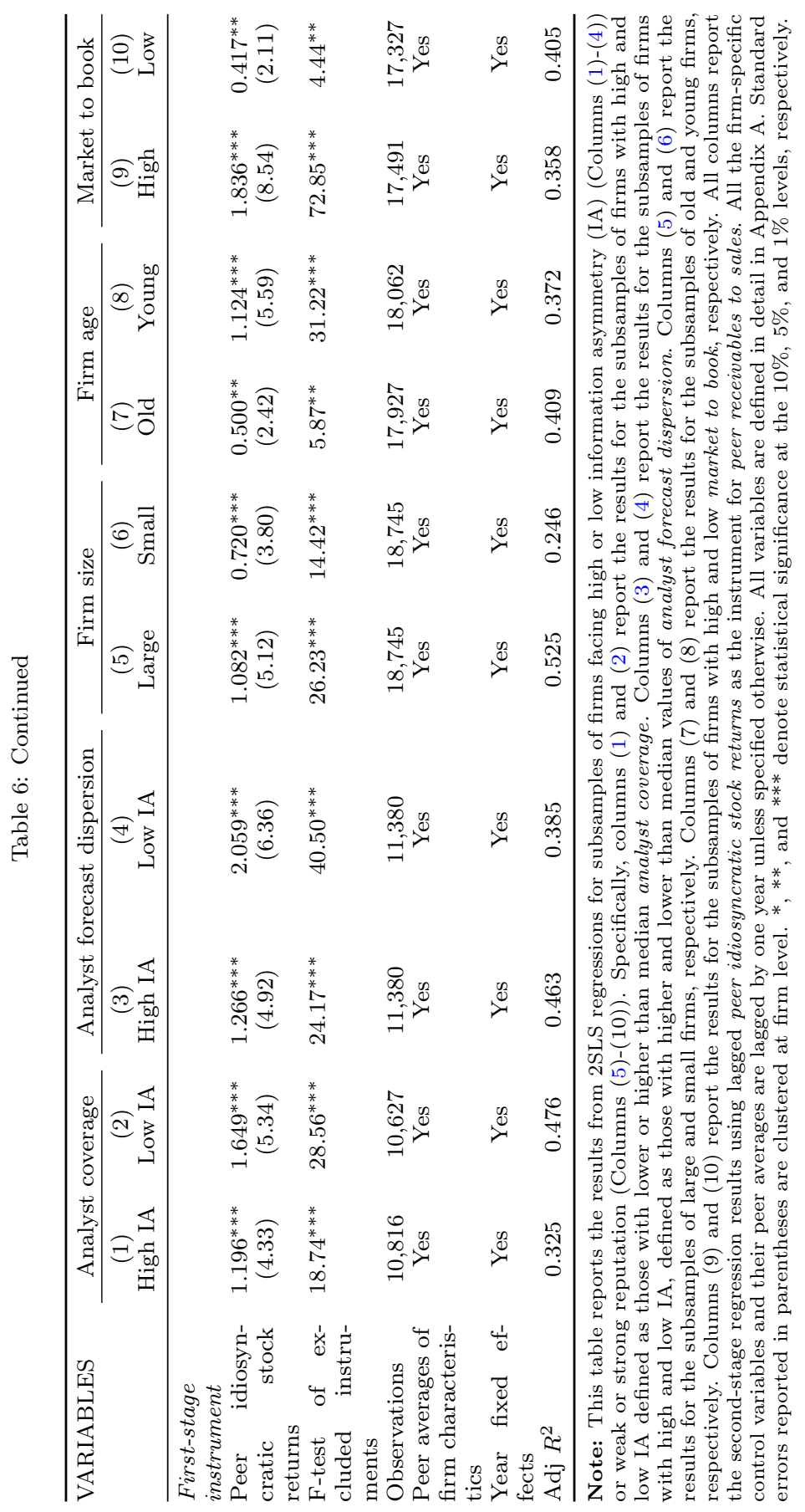


In the remainder of Table 6, we examine whether peer effects are driven by a related economic mechanism based on reputational motives. As discussed above, firms with a less established reputation need to provide buyers a quality guarantee in the form of trade credit, thereby allowing these buyers enough time to ascertain the product's quality (Love and Zaidi, 2010). Such suppliers also have strong incentives to mimic their peers' trade receivables to build their reputation, boost sales, and increase their market share. Empirically, Leary and Roberts (2014) show that mimicking behavior in capital structure is strongest among small, young, and less successful firms, potentially due to reputational motives. We thus also predict that peer influence on trade credit is most pronounced among such firms.

To test this conjecture, we partition, in columns (5)-(8) of Table 6, our sample into subsamples of large vs. small firms as well as old vs. young firms using the annual industry median values of firm size and age, respectively. In columns (9) and (10), we also consider firms with high market performance vs. those with low market performance using the annual industry median values of the market-to-book ratio. ${ }^{12}$ Small and young firms, as well as those with weak performance, are likely to have more reputational concerns and thus should exhibit more peer mimicking behavior. The results in columns (6) and (10) show no evidence of peer effects in trade credit among small and less successful firms, inconsistent with the reputational motives. In contrast, we document significant peer effects among large and successful firms, namely those with a more established reputation. In columns (7) and (8), we observe an opposite pattern of results where peer influence on trade credit exists only for young firms and not for old firms, consistent with the reputational motives. Overall, the results across all models in Table 6 show weak and mixed empirical support for the peer-based information channel.

\subsection{Role of Competition}

We next study whether mimicking behavior in trade credit provision is driven by the competition channel. If this channel is at play, we should expect peer effects in trade receivables to be stronger in industries with greater product market competition. To test this conjecture, we divide our sample into firms with high (low) competition based on three recently developed measures of product market competition, namely the TNIC Herfindahl index (TNIC HHI), product market similarity (Hoberg and Phillips, 2016), and product market fluidity (Hoberg et al., 2014). All three measures are based on textual analysis

\footnotetext{
${ }^{12}$ In some cases, firms with high market-to-book have more growth opportunities than assets-in-place. Hence, they may have a high degree of information asymmetry, as do small and young firms. However, as in Bharath et al. (2009) we argue that market-to-book is a crude measure of information asymmetry and thus inferior to the analyst-based measures we have already used.
} 
of 10-K filings, using the same approach adopted to develop TNIC described above. As such, they also have the same advantages as TNIC, namely, they are firm-specific and dynamic measures of product market competition. More precisely, the first measure, TNIC HHI, is the sum of the squared market shares of all firms operating in each TNIC industry. Product market similarity measures the similarity between a firm's product descriptions and those of peers, while product market fluidity captures how a firm's product market space changes in response to the competitive behavior of rivals. Low TNIC HHI index scores, high product market similarity, and high product market fluidity values are associated with a high degree of competitive pressure.

In columns (1) and (2) of Table 7, we partition the sample into firms with high (low) product market competition as those with below (above) annual industry median TNIC HHI index scores. In Columns (3)-(6), we define firms facing high (low) competitive pressure as those with above (below) annual industry median product market similarity and product market fluidity. Across all models, we find consistent results that peer effects in trade credit are statistically significant among firms operating in highly competitive industries (Columns (1), (3), and (5)). On the contrary, there is no evidence of such effects among firms facing low competitive pressure (Columns (2), (4), and (6)). Collectively, these results lend strong empirical support to the rivalry-based channel.

Overall, the results from our channel tests are consistent with the product market competition channel. Firms closely mimic their peers' trade credit policies when facing fierce competition from rivals. Contrariwise, the evidence on the peer-based information channel is rather mixed and weak, suggesting that peer effects in trade credit provision are unlikely to be explained by learning and reputational motives.

\section{Additional Analysis}

\subsection{Cross-Sectional Heterogeneity in Peer Effects}

In the first additional test, we turn to examine further cross-sectional heterogeneity in trade credit peer effects. Specifically, we study the types of firms, industries, and product markets where peer influence plays a more important role in shaping firms' trade receivables. Our analysis sheds further light into the mechanisms through which peer effects in trade credit operate.

\subsubsection{Results Conditional on Financial Constraints}

We first study whether there is cross-sectional variation in trade credit mimicking among constrained and unconstrained firms. Previous literature shows 


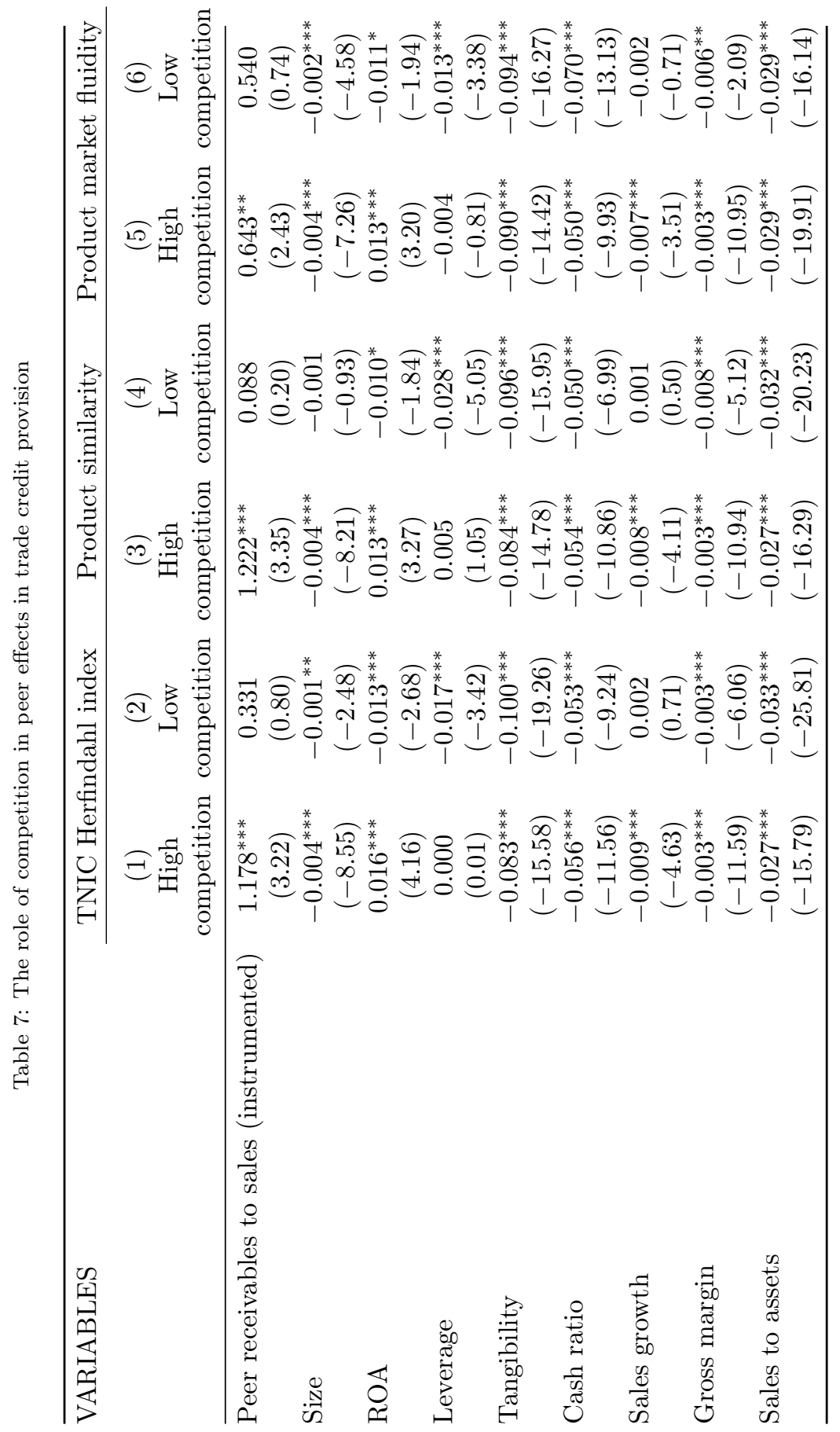




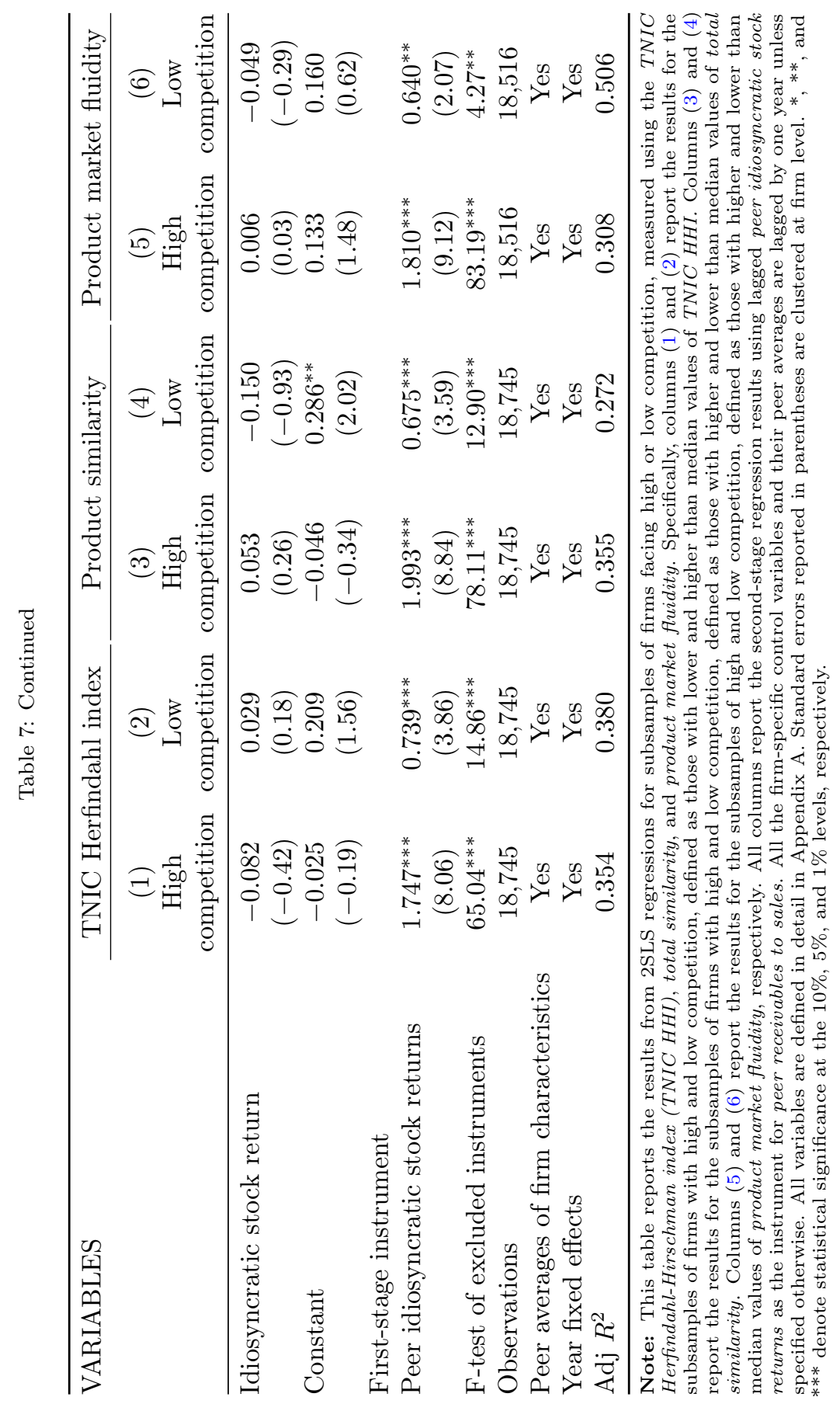


that access to external financial markets is an important determinant of a firm's trade credit provision (e.g., Petersen and Rajan, 1997; Giannetti et al., 2011; Abdulla et al., 2020). However, there are contradicting views regarding the impact of financial constraints on trade receivables and, particularly, the strength of peer influence on this policy. One view argues that, due to their limited access to capital markets and generally weaker financial position, constrained firms cannot easily extend more trade credit (e.g., Barrot, 2016) and thus will find it difficult to mimic their peers' trade receivables. In contrast, unconstrained firms can rely on their better access to external sources of capital to refinance accounts receivable (Petersen and Rajan, 1997; Abdulla et al., 2020), ${ }^{13}$ which, in turn, enables them to mimic peers' trade credit policies more easily. Furthermore, to the extent that unconstrained firms are typically larger and have stronger financial and operational capabilities, they are potentially better at collecting information about customers and monitoring them, managing credit risk, and enforcing payment in the case of customer default (Petersen and Rajan, 1997). In sum, this argument predicts that, compared to financially constrained firms, unconstrained suppliers will find it easier and less costly to mimic peers' trade credit policies.

The alternative view suggests that constrained firms, which tend to have a higher degree of information asymmetry and a weaker reputation, may follow peers' trade credit policies more closely, due to their strong learning and reputation-building motives. Managers that are less informed may learn more about the growth opportunities available on the market by observing peer firms' trade credit policies, which gives them strong incentives to mimic. In addition, constrained firms - including those that are small or young may imitate their peers' trade receivables to build a reputation. Overall, this argument indicates that trade credit peer effects may be more pronounced among constrained firms.

To examine the competing predictions developed above, we partition our sample into constrained and unconstrained firms, using a recent financial constraints measure based on the textual analysis of mandatory disclosures of firms' liquidity in 10-K fillings (Hoberg and Maksimovic, 2015). While there are other measures of financial constraints in the literature, ${ }^{14}$ for consistency, we opt for this particular measure as it is based on the same approach (textbased analysis) used to develop the TNIC, which we employ to identify peer firms.

\footnotetext{
${ }^{13}$ This argument is also consistent with the redistribution view where high-credit-quality firms tend to extend more trade credit to low-credit-quality customers (Schwartz, 1974; Nilsen, 2002).

${ }^{14}$ In unreported analysis, we also employ a commonly used measure of financial constraints, namely the size-age (SA) index (Hadlock and Pierce, 2010). The results are qualitatively similar.
} 


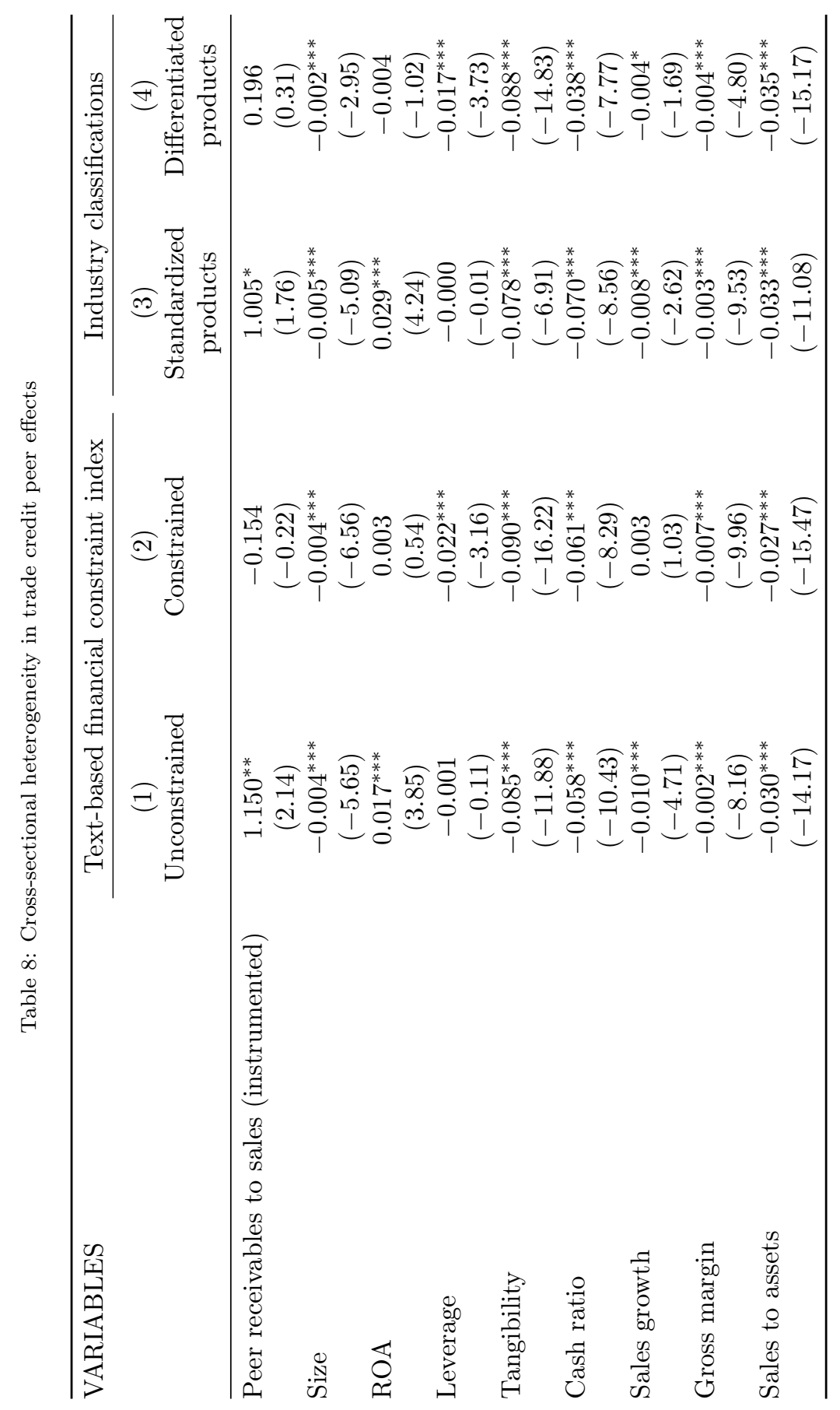




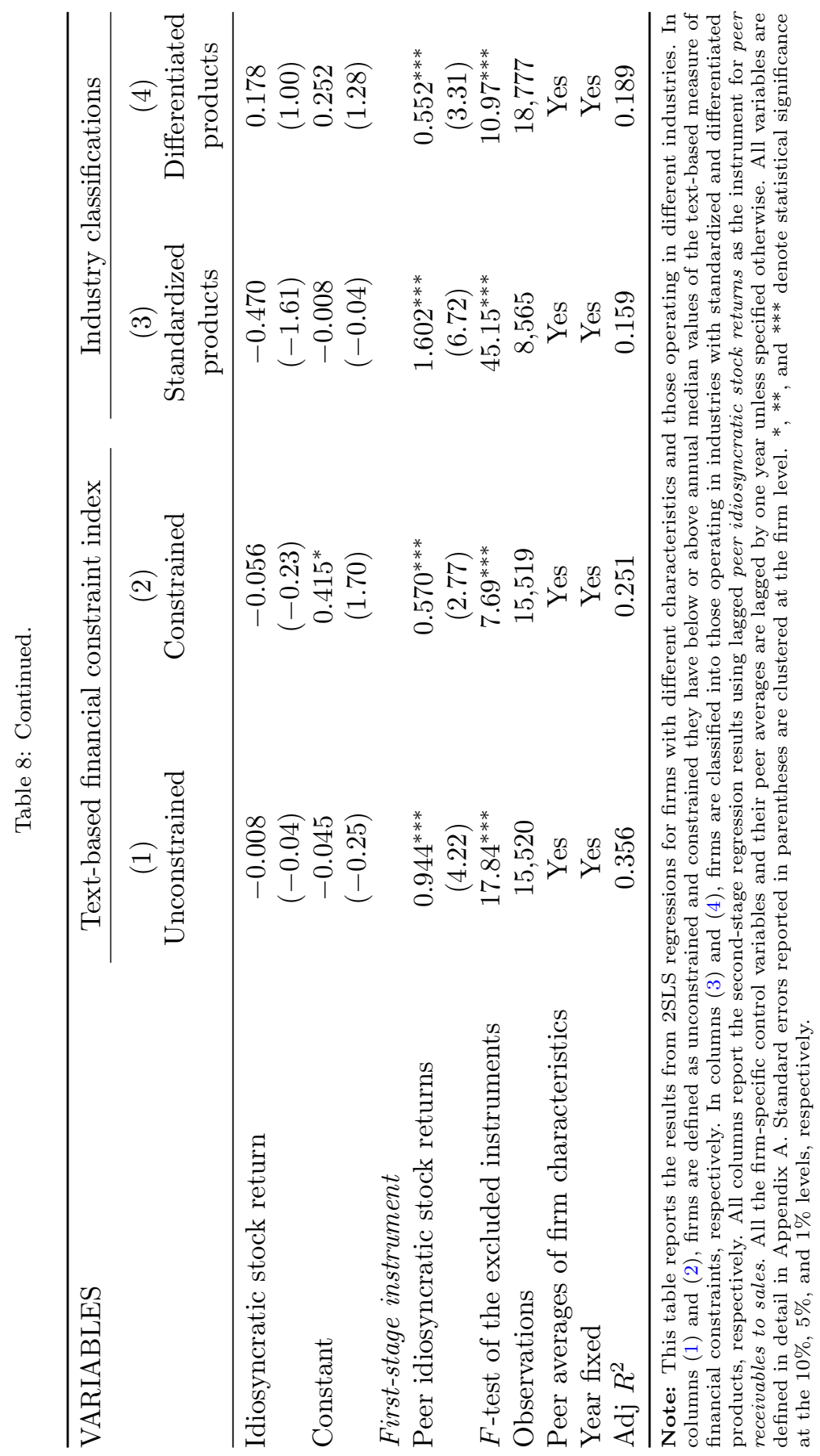


Columns (1) and (2) of Table 8 report the results from 2SLS regressions for unconstrained and constrained firms. In Column (1), we find that unconstrained firms mimic their peers' trade receivables. However, in Column (2), there is no evidence of such peer effects among constrained firms. Taken together, our results are consistent with the argument that firms with better access to financial markets are more able to mimic their peers' trade credit policies more closely. As in Section 5, our results do not support the learning and reputational motives, as we do not document any evidence of peer influence for financially constrained firms. The latter finding is in line with the idea that constrained suppliers have limited resources to mimic their peers. Another possible explanation is that constrained firms tend to hold less trade receivables as a precautionary measure when facing riskier future cash flows, an argument consistent with previous evidence in the cash holdings literature (Opler et al., 1999; Bates et al., 2009).

\subsubsection{Results Conditional on Industry and Product Characteristics}

The last two columns of Table 8 test whether heterogeneity in industry and product characteristics plays a role in firms' trade credit mimicking. We focus on the nature of the transacted good, namely, product differentiation vs. standardization, which may affect trade credit provision (Giannetti et al., 2011). We examine two conflicting views. First, the quality guarantee hypothesis predicts that suppliers operating in industries with differentiated goods display stronger behavior of peer mimicking. The rationale behind this prediction is that firms manufacturing differentiated products typically offer more trade credit to provide an implicit guarantee so that buyers can inspect their products and ascertain their quality before making payment (e.g., Long et al., 1993). Furthermore, such firms tend to have monopolistic power because it is difficult for customers to divert differentiated products for unintended purposes, switch suppliers, and default on their payment (Giannetti et al., 2011). To the extent that these firms have greater bargaining power and contract enforceability, they may have some incentives to extend more trade credit (McMillan and Woodruff, 1999; Petersen and Rajan, 1997). Taken together, these arguments suggest that suppliers of differentiated products can mimic their peers' trade credit policies more closely than suppliers of standardized products.

Second, the competition view predicts that firms manufacturing standardized products should exhibit more trade credit mimicking. The intuition is that industries where firms supply similar products, such as those that are standardized, face a greater level of competition. Hence, as discussed above, such suppliers are expected to have strong incentives to use trade credit as a competitive device to maintain their market share (Barrot, 2016; Fabbri and Klapper, 


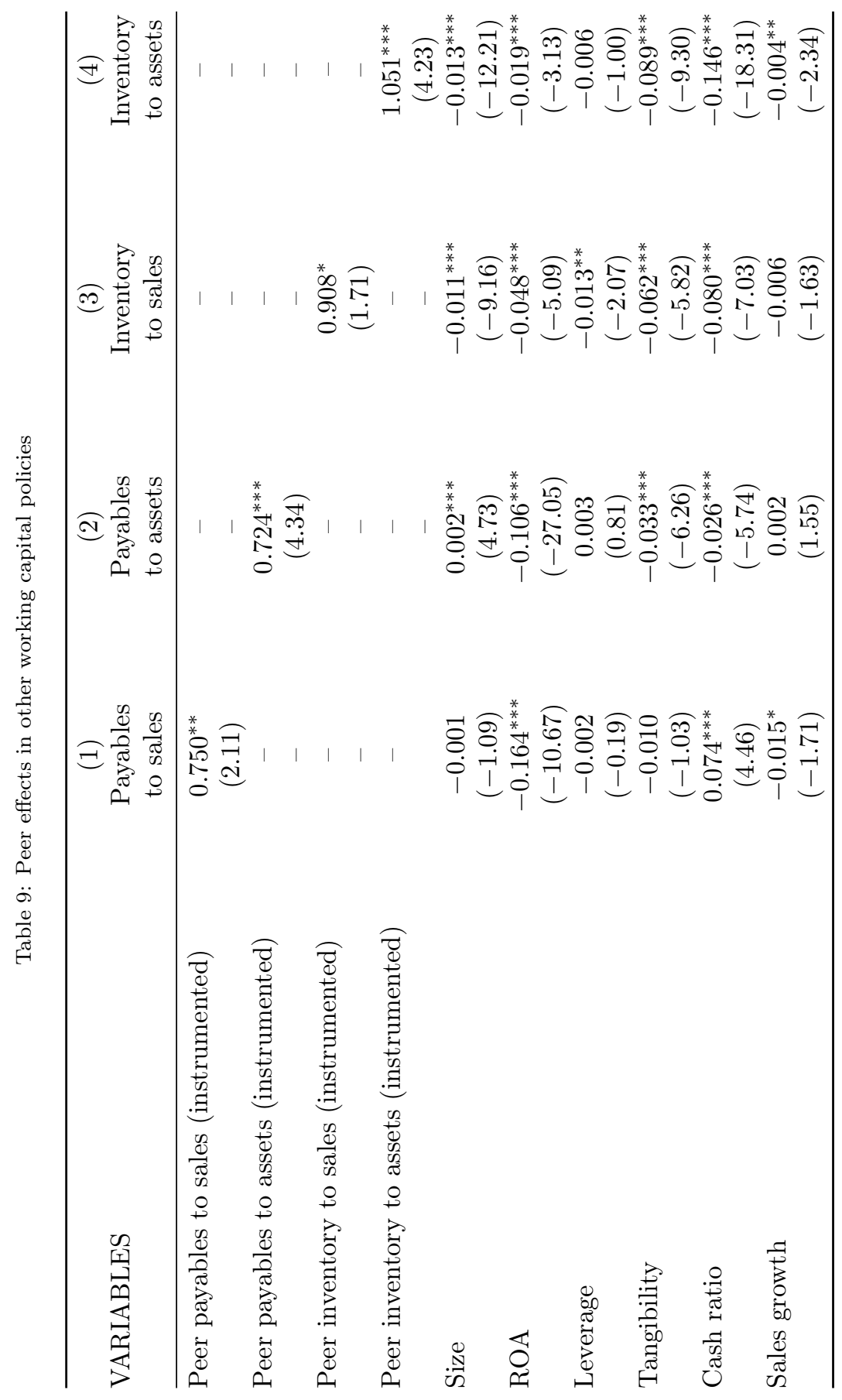




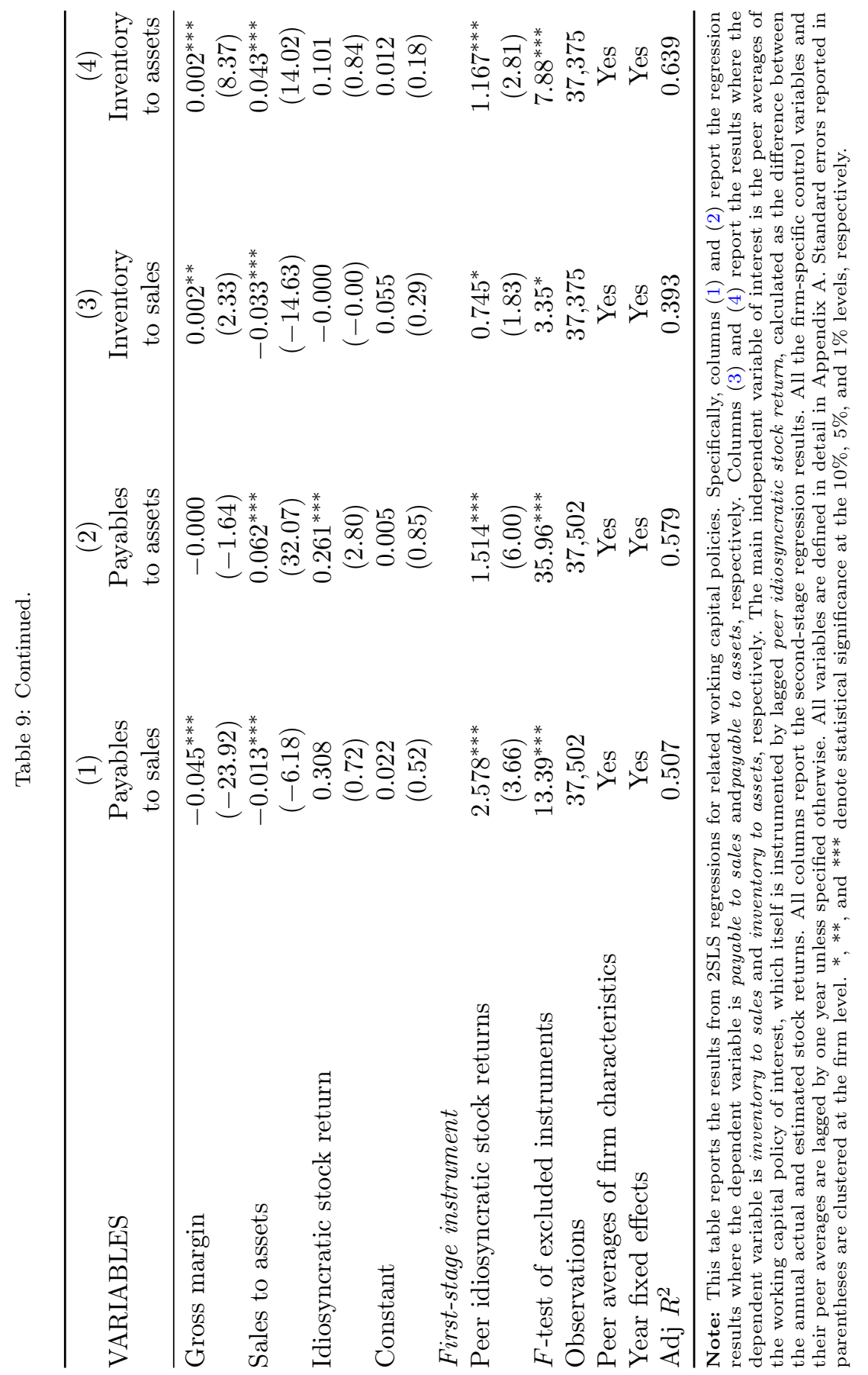


2016). However, this behavior leads to an equilibrium whereby suppliers tend to closely mimic one another's trade credit policies. The implication follows that peer effects should be stronger among suppliers of standardized goods.

To empirically investigate these conflicting views, we follow previous research (Rauch, 1999; Giannetti et al., 2011) and divide our sample into two groups of industries, those with standardized vs. differentiated products. ${ }^{15}$ Columns (3) and (4) of Table 8 report the 2SLS regression results for these two subsamples. Consistent with the competition argument, there is some evidence that firms supplying standardized products mimic their peers in trade credit decisions. However, we do not find evidence of mimicking behavior among suppliers of differentiated products. These findings provide further support for our earlier evidence that peer effects in trade credit operate mainly through the product market competition channel.

\subsection{Peer Effects in Other Working Capital Policies}

Since our evidence shows that firms mimic their peers' trade receivables, it is interesting to examine mimicking behavior in related working capital management policies. Hence, in our final test, we analyze whether firms mimic peer firms in two policies, namely trade payables and inventory. We reestimate our baseline model where we replace the dependent variable, accounts receivables, with accounts payables and inventory, respectively.

Table 9 presents the results from our 2SLS regressions. In columns (1) and (2), we study peer effects in accounts payable, measured as the ratio of trade payables to total sales and total assets (e.g., Petersen and Rajan, 1997; Fisman and Love, 2003; Cuñat, 2007; Giannetti et al., 2011), respectively. Consistent with our expectation, we find that the coefficients on both peer payables to sales and peer payables to assets are positive and statistically significant at the $1 \%$ level. In columns (3) and (4), we report the regression results for inventory, defined as inventory to sales and inventory to assets, respectively. The results are qualitatively similar to those in columns (1) and (2) as the coefficients on both peer inventory to sales and peer inventory to assets are positive and statistically significant at conventional levels. Taken together with our main finding, we conclude that peer effects exist in all key working capital policies, namely, accounts receivable, accounts payable, and inventory.

\section{Conclusions}

This study examines the role of peer firm behavior in shaping trade credit provision. We hypothesize that mimicking behavior in trade credit exists due

\footnotetext{
${ }^{15}$ See, Giannetti et al. (2011, p. 1296) for classifications of industries with standardized or differentiated goods.
} 
to learning and reputational motives as well as competitive pressure in the product market. Examining a sample of publicly listed US manufacturing firms, we find that firms do not make trade credit decisions in isolation but that they closely mimic peer firms, which is consistent with our hypothesis. Our results also hold after controlling for both firm and peer characteristics and are robust to using alternative measures of trade credit provision, different proxies for peer firms, and alternative instrumental variables.

In our cross-sectional analysis, we find that trade credit peer effects are concentrated among firms that face greater product market competition. There is, however, no evidence of mimicking behavior in trade receivables among firms with a high degree of information asymmetry. The results regarding firms with reputational concerns are also quite mixed, with peer effects only observed among large firms, those with high market performance, and young firms. Taken together, our findings suggest that trade credit mimicking is mainly driven by product market competition rather than peer-based learning and reputation-building considerations. Further analysis shows that suppliers exhibit strong mimicking behavior when they are financially unconstrained and operate in industries with standardized products. To the extent that unconstrained firms have less asymmetric information while those supplying standardized goods face greater competition, these results are again consistent with rivalry-based models.

Our study contributes to the literature on trade credit and peer effects. Existing research often focuses on firm-specific determinants of trade credit, with much less attention devoted to studying the impact of the external environment in which firms operate on trade receivables. We fill this gap by documenting novel evidence of peer effects in trade credit provision. Our research also adds to the growing literature on peer effects in corporate financial policies. We show that peer firm behavior plays an important role in shaping an important, yet overlooked, working capital policy, namely trade receivables. A practical implication of our research is that, as managers make trade credit decisions, they should pay considerable attention to the behavior of peer firms. 


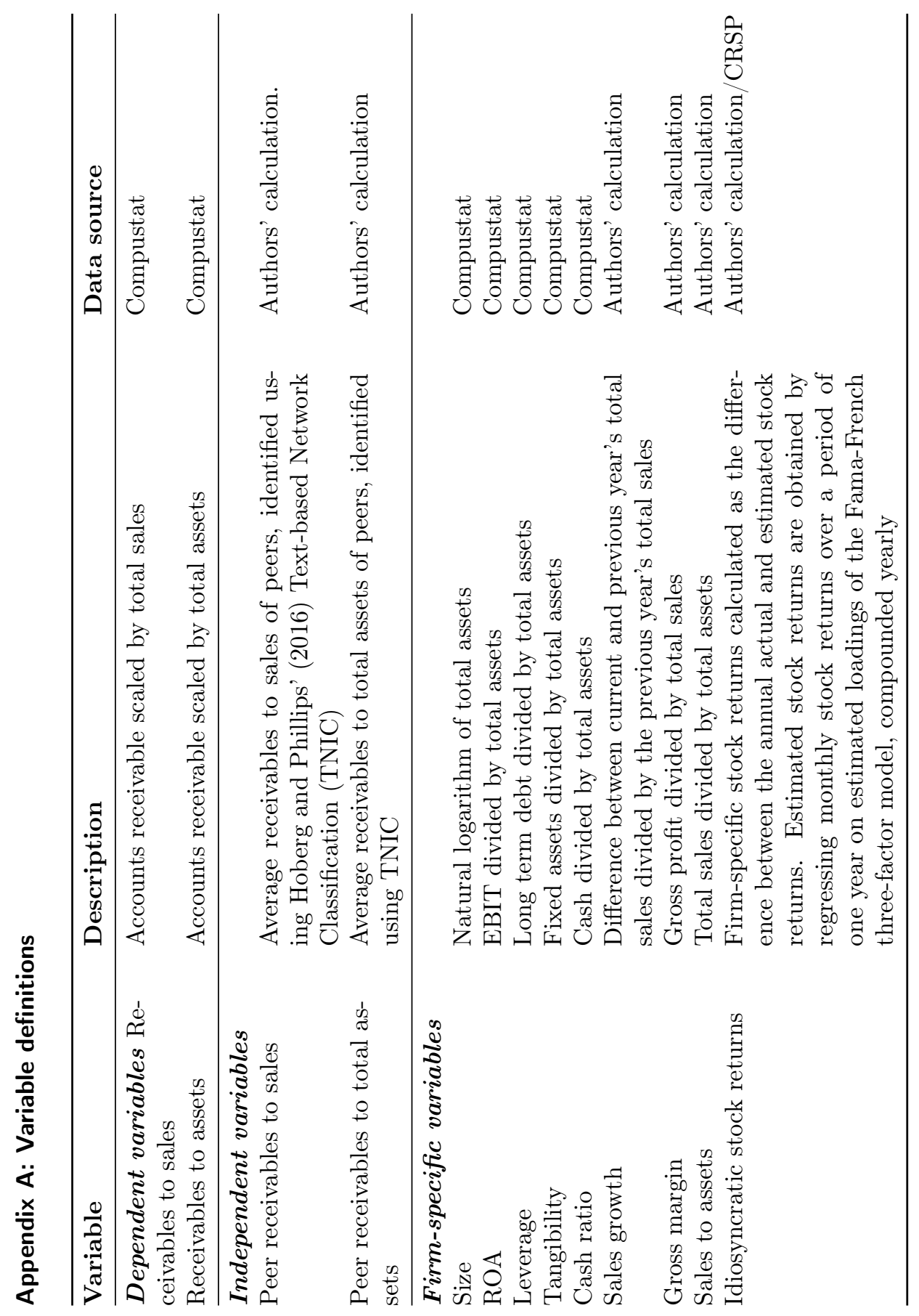




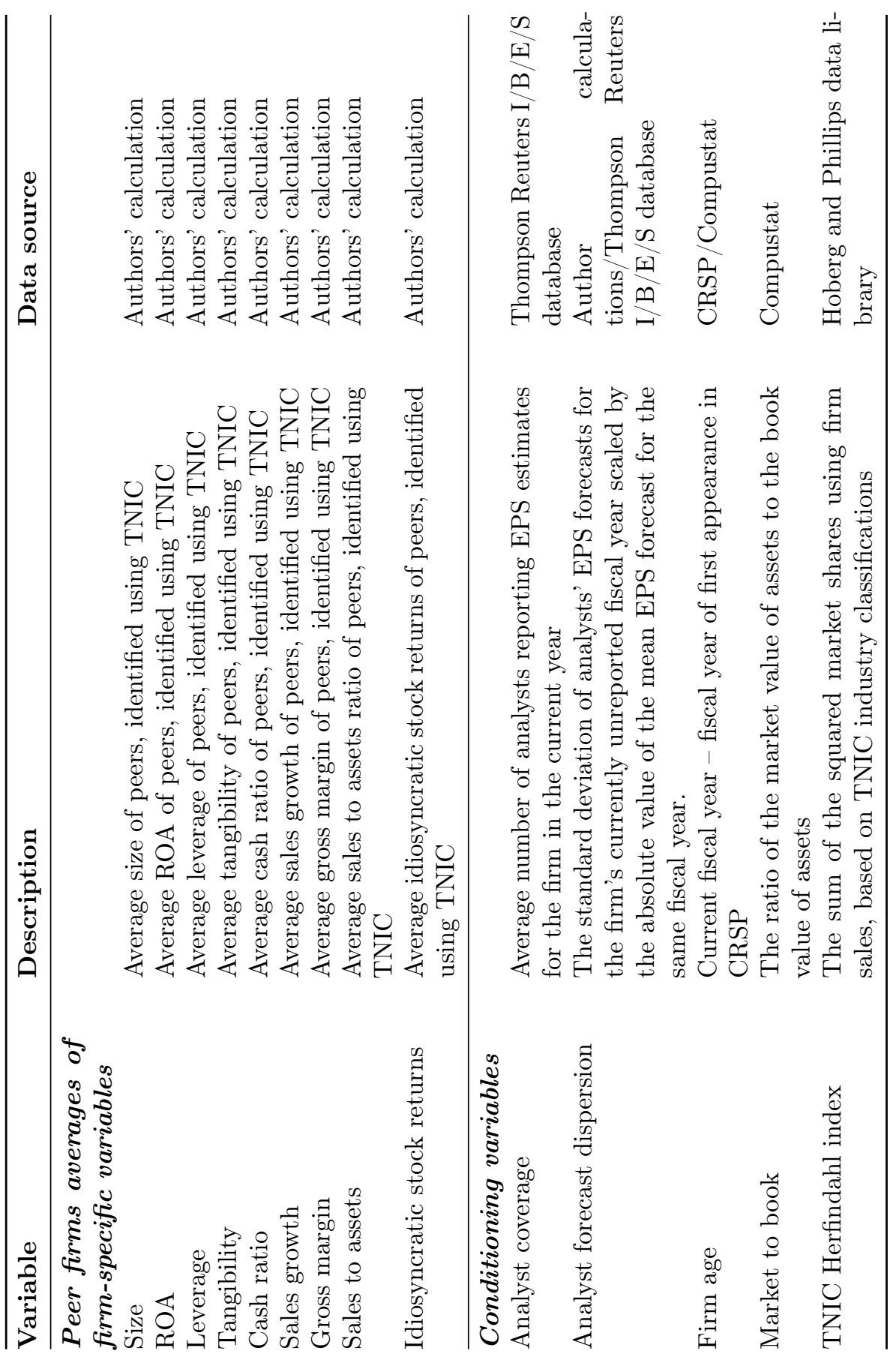




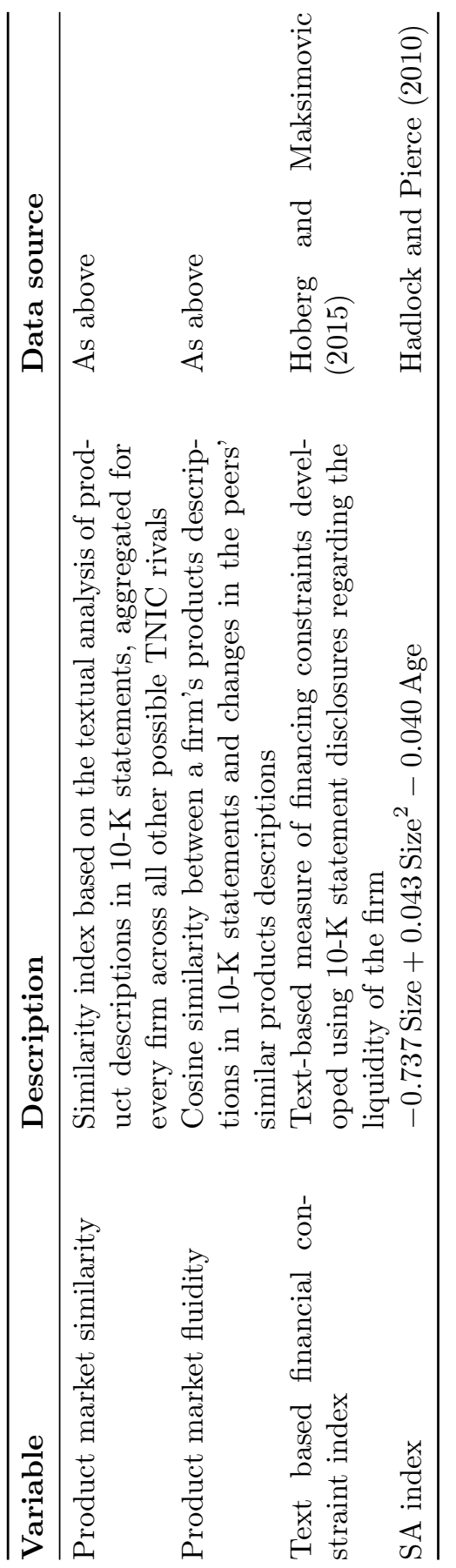




\section{References}

Abdulla, Y., V. A. Dang, and A. Khurshed. 2020. "Suppliers' listing status and trade credit provision". Journal of Corporate Finance. forthcoming.

Adhikari, B. and A. Agrawal. 2018. "Peer influence on payout policies". Journal of Corporate Finance. 48: 615-637.

Ahern, K. R., R. Duchin, and T. Shumway. 2014. "Peer effects in risk aversion and trust". Review of Financial Studies. 27(11): 3213-3240.

Aktas, N., E. Croci, and D. Petmezas. 2015. "Is working capital management value-enhancing? Evidence from firm performance and investments". Journal of Corporate Finance. 30: 98-113.

Albuquerque, A. M., G. D. Franco, and R. S. Verdi. 2013. "Peer choice in CEO compensation". Journal of Financial Economics. 108(1): 160-181.

Angrist, J. D. 2014. "The perils of peer effects". Labour Economics. 30(4): 98-108.

Atanasova, C. 2012. "How do firms choose between intermediary and supplier finance?" Financial Management. 41(1): 207-228.

Bailey, M., R. Cao, T. Kuchler, and J. Stroebel. 2018. "The economic effects of social networks: Evidence from the housing market". Journal of Political Economy. 126(6): 2224-2276.

Baker, M. and J. Wurgler. 2002. "Market timing and capital structure". Journal of Finance. 57(1): 1-30.

Barrot, J. N. 2016. "Trade credit and industry dynamics: Evidence from trucking firms". Journal of Finance. 71(5): 1975-2016.

Bates, T. W., K. M. Kahle, and R. M. Stulz. 2009. "Why do US firms hold so much more cash than they used to?" Journal of Finance. 64(5): 1985-2021.

Beshears, J., J. J. Choi, D. Laibson, B. C. Madrian, and K. L. Milkman. 2015. "The effect of providing peer information on retirement savings decisions". Journal of Finance. 70(3): 1985-2021.

Bharath, S. T., P. Pasquariello, and G. Wu. 2009. "Does asymmetric information drive capital structure decisions". Review of Financial Studies. 22(8): 3211-3243.

Biais, B. and C. Gollier. 1997. "Trade credit and credit rationing". Review of Financial Studies. 10(4): 903-937.

Bikhchandani, S., D. Hirshleifer, and I. Welch. 1992. "A theory of fads, fashion, custom, and cultural change as informational cascades". Journal of Political Economy. 100(5): 992-1026.

Billett, M., J. Garfinkel, and Y. Jiang. 2019. "The capital supply channel in SEO peer effects". Working Paper. Indiana University Kelly School of Business, University of Iowa, and California State University.

Bizjak, J. M., M. L. Lemmon, and L. Naveen. 2008. "Does the use of peer groups contribute to higher pay and less efficient compensation?" Journal of Financial Economics. 90(2): 152-168. 
Bougheas, S., M. Simona, and P. Mizen. 2009. "Corporate trade credit and inventories: New evidence of a trade-off from accounts payable and receivable". Journal of Banking and Finance. 33: 300-307.

Box, T., R. Davis, M. Hill, and C. Lawrey. 2018. "Operating performance and aggressive trade credit policies". Journal of Banking and Finance. 89: $192-208$.

Bratten, B., J. L. Payne, and W. B. Thomas. 2015. "Earnings management: Do firms play "follow the leader"?" Contemporary Accounting Research. 33(2): 616-643.

Brennan, M. J., V. Maksimovics, and J. Zechner. 1988. "Vendor financing". Journal of Finance. 43(5): 1127-1141.

Brick, I. E. and W. K. Fung. 1984. "Taxes and the theory of trade debt". Journal of Finance. 39(4): 1169-1176.

Burkart, M. and T. Ellingsen. 2004. "In-kind finance: a theory of trade credit". American Economic Review. 94(3): 569-590.

Bursztyn, L., F. Ederer, B. Ferman, and N. Yuchtman. 2014. "Understanding mechanisms underlying peer effects: Evidence from a field experiment on financial decisions". Econometrica. 82(4): 1273-1301.

Bustamante, M. C. and L. Frésard. 2019. "Does firm investment respond to peers' investment?" Working Paper. University of Maryland and University of Lugano.

Cao, J., H. Liang, and X. Zhan. 2019. "Peer effects of corporate social responsibility". Management Science. 65(12): 5487-5503.

Carhart, M. M. 1997. "On persistence in mutual fund performance". Journal of Finance. 52(1): 57-82.

Casey, E. and C. M. O'Toole. 2014. "Bank-lending constraints, trade credit and alternative financing during the financial crisis: Evidence from European SMEs". Journal of Corporate Finance. 27: 173-193.

Chen, Y.-W., K. Chan, and Y. Chang. 2019. "Peer effects on corporate cash holdings". International Review of Economics and Finance. 61: 213-227.

Chod, J., E. Lyandres, and S. A. Yang. 2019. "Trade credit and supplier competition". Journal of Financial Economics. 131(2): 484-505.

Choi, W. G. and Y. Kim. 2005. "Trade credit and the effect of macro-financial shocks: Evidence from US panel data". Journal of Financial and Quantitative Analysis. 40(04): 897-925.

Cooper, M. J., H. Gulen, and M. J. Schill. 2008. "Asset growth and the cross-section of stock returns". Journal of Finance. 63(4): 1609-1651.

Cull, R., L. C. Xu, and T. Zhu. 2009. "Formal finance and trade credit during China's transition". Journal of Financial Intermediation. 18(2): 173-192.

Cuñat, V. 2007. "Trade credit: Suppliers as debt collectors and insurance providers". Review of Financial Studies. 20(2): 491-527.

Dass, N., J. R. Kale, and V. Nanda. 2015. "Trade credit, relationship-specific investment, and product market power". Review of Finance. 19: 1867-1923. 
De Bondt, W. F. 1999. "Herding in analyst earnings forecasts: evidence from the United Kingdom". European Financial Management. 5(2): 143-163.

Decaire, J., E. Gilje, and J. Taillard. 2019. "Real option exercise: Empirical evidence". Review of Financial Studies. forthcoming.

Deloof, M. 2003. "Does working capital management affect profitability of Belgian firms?" Journal of Business Finance and Accounting. 30(3-4): 573588.

Deloof, M. and M. Jegers. 1996. "Trade credit, product quality, and intragroup trade: Some European evidence". Financial Management. 25(3): 33-43.

Devenow, A. and I. Welch. 1996. "Rational herding in financial economics". European Economic Review. 40(3): 603-615.

Dimmock, S. G., W. C. Gerken, and N. P. Graham. 2018. "Is fraud contagious? Co-worker influence on misconduct by financial advisors". Journal of Finance. 73(3): 1417-1450.

Dougal, C., C. A. Parsons, and S. Titman. 2015. "Urban vibrancy and corporate growth". Journal of Finance. 70(1): 163-210.

El Ghoul, S. and X. Zheng. 2016. "Trade credit provision and national culture". Journal of Corporate Finance. 41: 475-501.

Emery, G. W. 1984. "A pure financial explanation for trade credit". Journal of Financial and Quantitative Analysis. 19(3): 271-285.

Emery, G. W. 1987. "An optimal financial response to variable demand". Journal of Financial and Quantitative Analysis. 22(2): 209-225.

Fabbri, D. and L. F. Klapper. 2016. "Bargaining power and trade credit". Journal of Corporate Finance. 41: 66-80.

Fabbri, D. and A. M. C. Menichini. 2010. "Trade credit, collateral liquidation, and borrowing constraints". Journal of Financial Economics. 96(3): 413432.

Fairburst, D. and Y. Nam. 2018. "Corporate governance and financial peer effects". Financial Management. 49(1): 235-263.

Fama, E. F. and K. R. French. 1993. "Common risk factors in the returns on bonds and stocks". Journal of Financial Economics. 33(1): 3-53.

Ferrando, A. and K. Mulier. 2013. "Do firm use the trade credit channel to manage growth?" Journal of Banking and Finance. 37(8): 3035-3046.

Ferris, J. S. 1981. "A transactions theory of trade credit use". Quarterly Journal of Economics. 96(2): 243-270.

Fisman, R. and I. Love. 2003. "Trade credit, financial intermediary development, and industry growth". Journal of Finance. 58(1): 353-374.

Fisman, R. and M. Raturi. 2004. "Does competition encourage credit provision? Evidence from African trade credit relationships". Review of Economics and Statistics. 86(1): 345-352.

Foucault, T. and L. Frésard. 2014. "Learning from peers' stock prices and corporate investment". Journal of Financial Economics. 111(3): 554-577. 
Francis, B. B., I. Hasan, K. John, and M. Waisman. 2016a. "Urban agglomeration and CEO compensation". Journal of Financial and Quantitative Analysis. 51(6): 1925-1953.

Francis, B. B., I. Hasan, and G. Kostova. 2016b. "When do peers matter? A cross-country perspective". Journal of International Money and Finance. 69: 364-389.

Gao, W., L. Ng, and Q. Wang. 2011. "Does corporate headquarters location matter for firm capital structure?" Financial Management. 40(1): 113-138.

Garcia-Appendini, E. and J. Montoriol-Garriga. 2013. "Firms as liquidity providers: Evidence from the 2007-2008 financial crisis". Journal of Financial Economics. 109(1): 272-291.

García-Teruel, P. J. and P. Martínez-Solano. 2010a. "A dynamic approach to accounts receivable: A study of Spanish SMEs". European Financial Management. 16(3): 400-421.

García-Teruel, P. J. and P. Martínez-Solano. 2010b. "Determinants of trade credit: A comparative study of European SMEs". International Small Business Journal. 28: 215-233.

Georgarakos, D., M. Haliassos, and G. Pasini. 2014. "Household debt and social interactions". Review of Financial Studies. 27(5): 1404-1433.

Giannetti, M., M. Burkart, and T. Ellingsen. 2011. "What you sell is what you lend? Explaining trade credit contracts". Review of Financial Studies. 24(4): 1261-1298.

Gleason, C. A., N. T. Jenkins, and W. B. Johnson. 2008. "The contagion effects of accounting restatements". Accounting Review. 83(1): 83-110.

Gonçalves, A. B., R. F. Schiozer, and H. H. Sheng. 2018. "Trade credit and product market power during a financial crisis". Journal of Corporate Finance. 49: 308-323.

Goto, S., G. Xiao, and Y. Xu. 2015. "As told by the supplier: Trade credit and the cross section of stock returns". Journal of Banking and Finance. 60: 296-309.

Grennan, J. 2019. "Dividend payments as a response to peer influence". Journal of Financial Economics. 131(3): 549-570.

Gyimah, D., M. Machokoto, and A. Sikochi. 2020. "Peer influence on trade credit". Journal of Corporate Finance. 64: 101685-.

Hadlock, C. J. and J. R. Pierce. 2010. "New evidence on measuring financial constraints: Moving beyond the KZ index". Review of Financial Studies. 23(5): 1909-1940.

Healy, P. M. and K. G. Palepu. 2001. "Information asymmetry, corporate disclosure, and the capital markets: A review of the empirical disclosure literature". Journal of Accounting and Economics. 31(1-3): 405-440.

Heimer, R. Z. 2016. "Peer pressure: Social interaction and the disposition effect". Review of Financial Studies. 29(11): 3177-3209. 
Hill, M. D., G. W. Kelly, and G. B. Lockhart. 2012. "Shareholder returns from supplying trade credit". Financial Management. 41(1): 255-280.

Hirshleifer, D. and S. Hong Teoh. 2003. "Herd behaviour and cascading in capital markets: A review and synthesis". European Financial Management. 9(1): 25-66.

Hoberg, G. and V. Maksimovic. 2015. "Redefining financial constraints: a text-based analysis". Review of Financial Studies. 28(5): 1312-1352.

Hoberg, G. and G. Phillips. 2010. "Product market synergies and competition in mergers and acquisitions: A text-based analysis". Review of Financial Studies. 23(10): 3773-3811.

Hoberg, G. and G. Phillips. 2016. "Text-based network industries and endogenous product differentiation". Journal of Political Economy. 124(5): 1423-1465.

Hoberg, G., G. Phillips, and N. Prabhala. 2014. "Product market threats, payouts, and financial flexibility". Journal of Finance. 69(1): 293-324.

Hott, C. 2009. "Herding behavior in asset markets". Journal of Financial Stability. 5(1): 35-56.

Husted, B. W., D. Jamali, and W. Saffar. 2015. "Near and dear? The role of location in CSR engagement". Strategic Management Journal. 37(10): 2050-2070.

Jenter, D. and F. Kanaan. 2015. "CEO turnover and relative performance evaluation". Journal of Finance. 70(5): 2155-2184.

Jiraporn, P., N. Jiraporn, A. Boeprasert, and K. Chang. 2014. "Does corporate social responsibility (CSR) improve credit ratings? Evidence from geographic identification". Financial Management. 43(3): 505-531.

Kaustia, M. and V. Rantala. 2015. "Social learning and corporate peer effects". Journal of Financial Economics. 117(3): 449-670.

Kieschnick, R., M. Laplante, and R. Moussawi. 2013. "Working capital management and shareholders' wealth". Review of Finance. 17(5): 1827-1852.

Kim, Y., M. Lacina, and M. S. Park. 2008. "Positive and negative information transfers from management forecasts". Journal of Accounting Research. 46(4): 885-908.

Klapper, L., L. Laeven, and R. Rajan. 2012. "Trade credit contracts". Review of Financial Studies. 25(3): 838-867.

Lamont, O. 2000. "Investment plans and stock returns". Journal of Finance. 55(6): 2719-2745.

Leary, M. T. and M. R. Roberts. 2014. "Do peer firms affect corporate financial policy?" Journal of Finance. 69(1): 139-178.

Lee, Y. W. and J. D. Stowe. 1993. "Product risk, asymmetric information, and trade credit". Journal of Financial and Quantitative Analysis. 28(2): $285-300$.

Lieberman, M. B. and S. Asaba. 2006. "Why do firms imitate each other?" Academy of Management Review. 31(2): 366-385. 
Liu, L. X., T. M. Whited, and L. Zhang. 2009. "Investment-based expected stock returns". Journal of Political Economics. 117(6): 1105-1139.

Long, M. S., I. B. Malitz, and S. A. Ravid. 1993. "Trade credit, quality guarantees, and product marketability". Financial Management. 22(4): $117-127$.

Love, I., L. A. Preve, and V. Sarria-Allende. 2007. "Trade credit and bank credit: Evidence from recent financial crises". Journal of Financial Economics. 83(2): 453-469.

Love, I. and R. Zaidi. 2010. "Trade credit, bank credit and financial crisis". International Review of Finance. 10(1): 125-147.

MacKay, P. and G. M. Phillips. 2005. "How does industry affect firm financial structure?" Review of Financial Studies. 18(4): 1433-1466.

Manski, C. F. 1993. "Identification of endogenous social effects: The reflection problem". Review of Economic Studies. 60(3): 531-542.

Mateut, S., S. Bougheas, and P. Mizen. 2006. "Trade credit, bank lending and monetary policy transmission". European Economic Review. 50(3): 603-629.

McGuinness, G., T. Hogan, and R. Powell. 2018. "European trade credit use and SME survival". Journal of Corporate Finance. 49: 81-103.

McMillan, J. and C. Woodruff. 1999. "Interfirm relationships and informal credit in Vietnam". Quarterly Journal of Economics. 114(4): 1285-1320.

Meltzer, A. H. 1960. "Mercantile credit, monetary policy, and size of firms". Review of Economics and Statistics. 42(4): 429-437.

Mian, S. L. and C. W. Smith. 1992. "Accounts receivable management policy: Theory and evidence". Journal of Finance. 47(1): 169-200.

Molina, C. A. and L. A. Preve. 2009. "Trade receivables policy of distressed firms and its effect on the costs of financial distress". Financial Management. 38(3): 663-686.

Morck, R., A. Shleifer, and R. W. Vishny. 1989. "Alternative mechanisms for corporate control". American Economic Review. 79(4): 842-852.

Murfin, J. and K. Njoroge. 2014. "The implicit costs of trade credit borrowing by large firms". Review of Financial Studies. 28(1): 112-145.

Myers, S. C. 1977. "Determinants of corporate borrowing". Journal of Financial Economics. 5(2): 147-175.

Myers, S. C. 1984. "The capital structure puzzle". Journal of Finance. 39(3): $574-592$.

Ng, C. K., J. K. Smith, and R. L. Smith. 1999. "Evidence on the determinants of credit terms used in interfirm trade". Journal of Finance. 54(3): 11091129.

Nilsen, J. H. 2002. "Trade credit and the bank lending channel". Journal of Money, Credit, and Banking. 34(1): 226-253.

Niskanen, J. and M. Niskanen. 2006. "The determinants of corporate trade credit policies in a bank-dominated financial environment: The case of Finnish small firms". European Financial Management. 12(1): 81-102. 
Opler, T., L. Pinkowitz, R. Stulz, and R. Williamson. 1999. "The determinants and implications of corporate cash holdings". Journal of Financial Economics. 52(1): 3-46.

Ouimet, P. and G. Tate. 2019. "Learning from Coworkers: Peer effects on individual investment decisions". Journal of Finance. 75(1): 133-172.

Parsons, C. A., J. Sulaeman, and S. Titman. 2018. "The geography of financial misconduct". Journal of Finance. 73(5): 2087-2137.

Petersen, M. A. and R. G. Rajan. 1997. "Trade credit: Theories and evidence". Review of Financial Studies. 10(3): 661-691.

Pike, R., N. S. Cheng, K. Cravens, and D. Lamminmaki. 2005. "Trade credit terms: Asymmetric information and price discrimination evidence from three continents". Journal of Business Finance and Accounting. 32(5\&6): $1197-1236$.

Rauch, J. E. 1999. "Networks versus markets in international trade". Journal of International Economics. 48(1): 7-35.

Scharfstein, D. S. and J. C. Stein. 1990. "Herd behavior and investment". American Economic Review. 80(3): 465-479.

Schwartz, R. A. 1974. "An economic model of trade credit". Journal of Financial and Quantitative Analysis. 9(4): 643-657.

Seo, H. 2017. "Peer effects in corporate disclosure decisions". Working Paper. National University of Singapore.

Smith, J. K. 1987. "Trade credit and informational asymmetry". Journal of Finance. 42(4): 863-872.

Titman, S., K. J. Wei, and F. Xie. 2004. "Capital investments and stock returns". Journal of Financial and Quantitative Analysis. 39(4): 677-700.

Trueman, B. 1994. "Analyst forecasts and herding behavior". Review of Financial Studies. 7(1): 97-124.

Welch, I. 2000. "Herding among security analysts". Journal of Financial Economics. 58(3): 369-396.

Welch, I. 2004. "Capital structure and stock returns". Journal of Political Economy. 112(1): 106-131.

Wilner, B. S. 2000. "The exploitation of relationships in financial distress: The case of trade credit". The Journal of Finance. 55(1): 153-178.

Wilson, N. and B. Summers. 2002. "Trade credit terms offered by small firms: Survey evidence and empirical analysis". Journal of Business and Finance Accounting. 29(3-4): 317-335. 